INRA Prod. Anim., 2007, 20 (2), 163-176

\title{
Effet des nutriments énergétiques sur la production et la teneur en matière grasse du lait de vache
}

\author{
H. RULQUIN, C. HURTAUD, S. LEMOSQUET, J.-L. PEYRAUD \\ INRA, Agrocampus, UMR1080 Production du lait, F-35590 Saint-Gilles, France
}

Courriel :henri.rulquin@rennes.inra.fr

Le taux butyreux varie en fonction de nombreux facteurs, dont l'alimentation qui a fait l'objet de très nombreuses études. Quatre théories successives ont vu le jour sur les moyens de le contrôler. Cependant, aucune d'elles ne permet de prédire actuellement de façon satisfaisante le taux butyreux ou la production de matière grasse. Une cinquième théorie est proposée.

La valorisation de la matière grasse laitière est aujourd'hui de plus en plus difficile du fait de l'évolution récente de l' «OCM lait» et de la réforme de la PAC avec la fin des restitutions. Les perspectives d'accroissement de la consommation de matières grasses laitières étant modérées (voire nulles), il sera probablement nécessaire à l'avenir de diminuer la production en baissant le taux butyreux des laits. En effet, une diminution par le biais de la production de lait entraînerait une diminution de la production de protéines qui sont bien valorisées par l'industrie fromagère et la production de caséinate. L'enjeu sera donc d'augmenter le rapport taux protéique sur taux butyreux. Les différents facteurs agissant sur la composition du lait ont déjà fait l'objet de nombreuses revues. Sommairement, les taux varient en fonction : de la race et de la variabilité intra-race (Bonaïti 1985), du stade de lactation et de l'âge, de la saison et de l'alimentation (Coulon et al 1991, Journet et Chilliard 1985). A l'échelle de l'animal, 3 voies peuvent être envisagées pour modifier le rapport taux protéique sur taux butyreux : 2 voies génétiques (inter et intra race) et une voie alimentaire. A l'échelle du troupeau, il est possible de jouer fortement via la répartition des vêlages.

Le changement de race (Montbéliarde $v s$ Holstein) permet d'augmenter le rapport taux protéique sur taux butyreux, mais cela va généralement de pair avec une diminution du volume de lait. En revanche, au sein d'une race, il est actuellement possible de sélectionner des taureaux qui diminuent le taux butyreux sans modifier le taux protéique tout en apportant des gains de production laitière. Ainsi en race Holstein, il existe parmi les 100 meilleurs taureaux, des taureaux qui diminuent le taux butyreux de $-0,5$ à - $6,0 \mathrm{~g} / \mathrm{kg}$ tout en accroissant le taux protéique de $+0,5$ à $3,0 \mathrm{~g} / \mathrm{kg}$ respectivement (Institut de l'Elevage 2005). Les recherches sur les gènes majeurs avec la découverte du DGAT1 offrent pour l'avenir de sérieuses pistes pour réduire le taux butyreux par la sélection génétique (Kucerova et al 2006). Toutefois, le gène DGAT1 touche aussi la teneur en protéine des laits (Kucerova et al 2006).

Le taux butyreux est un critère relativement variable d'un jour à l'autre, car il est fortement lié à la traite (son niveau variant de 1 à 10 entre le début et la fin de traite). Cependant, il est, parmi les solides du lait, l'élément qui est le plus fortement et le plus rapidement modifiable par l'alimentation (Hoden et Coulon 1991). En effet, il est connu depuis longtemps (années 40), que des rations riches en aliments concentrés ou en lipides insaturés apportés par les aliments concentrés ou le fourrage (herbe verte), ou des rations contenant des aliments dont les particules sont de petite taille peuvent causer des chutes importantes du taux butyreux (- $10 \mathrm{~g} / \mathrm{kg}$ voire - $30 \mathrm{~g} / \mathrm{kg})$. Ces baisses appelées «low-fat milk syndrome» dans les pays de langue anglaise ont fait l'objet de nombreuses revues dans ces pays (Bauman et Griinari 2001, 2003, Davis et Brown 1970, Van Soest 1963). Les connaissances accu- mulées sur la synthèse des matières grasses du lait permettent de proposer des pistes pour comprendre ces chutes du taux butyreux. La matière grasse du lait est constituée à $98 \%$ par des triglycérides eux-mêmes constitués d'acides gras et de glycérol. Les acides gras du lait à chaîne de carbone courte à longue $(\mathrm{C} 4: 0$ à $\mathrm{C} 15: 0)$ et la moitié du C16:0 dépendent de la fourniture d'acétate (origine endogène et provenant de l'acétate ruminal) et de $\beta$-hydroxybutyrate (origine endogène et provenant du butyrate ruminal). La moitié du C16:0 et la totalité des acides gras dont la chaîne carbonée est supérieure à 18 atomes de carbone proviennent des acides gras à longues chaînes carbonées transportés par les chylomicrons (origine exogène), les VLDL (origine endogène) et l'albumine (AGNE) (origine endogène) (Chilliard et Sauvant 1987). Le glycérol nécessaire à la synthèse des triglycérides du lait est fourni par le glucose capté par la mamelle et le glycérol libéré par l'hydrolyse des chylomicrons et des VLDL (figure 1).

Tous les facteurs alimentaires susceptibles de faire varier ces précurseurs ou leur utilisation intra-mammaire sont donc susceptibles de faire varier le taux butyreux. Les recherches conduites en nutrition depuis une cinquantaine d'années ont mis en évidence 7 nutriments modulant le taux butyreux. Il s'agit de 3 acides gras volatils du rumen (acétate, propionate et butyrate), du glucose digéré dans l'intestin et de 2 acides gras (trans $_{10} \mathrm{C} 18: 1$ et trans 10, cis $_{12} \mathrm{C} 18: 2$ ou trans $10, \operatorname{cis}_{12}$ CLA) et le reste des 
Figure 1. Rôles schématiques des nutriments intervenants dans la synthèse des matières grasses du lait.

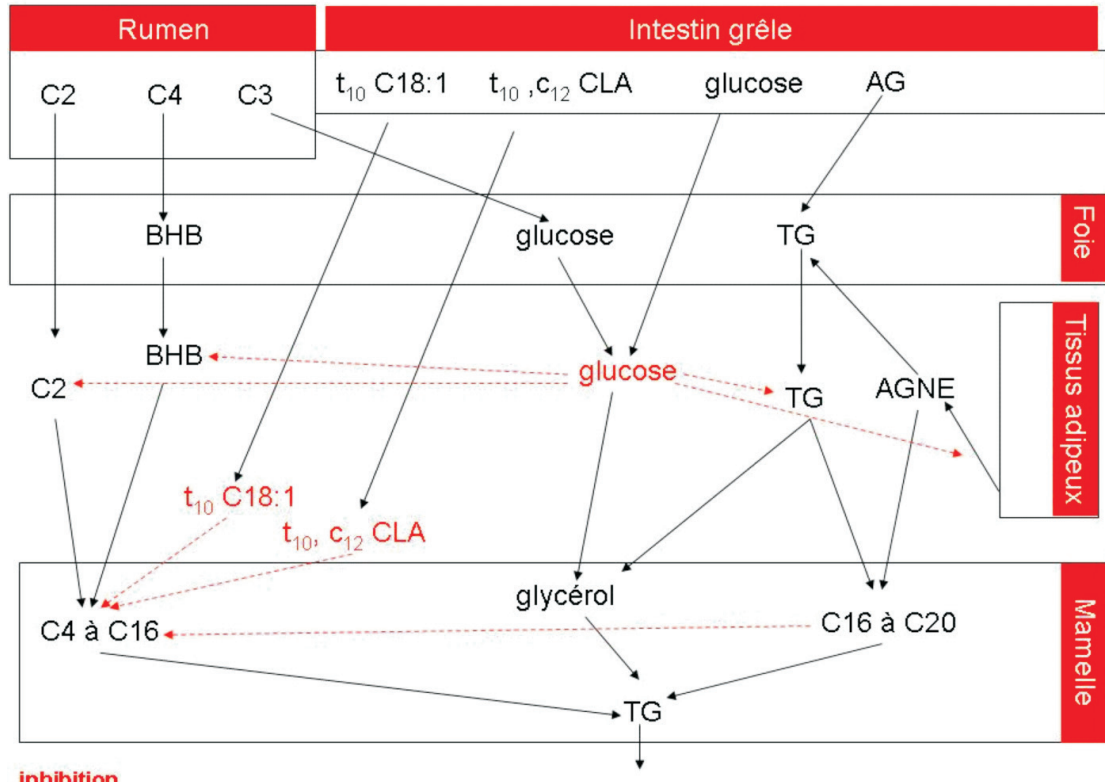

inhibition

$\mathrm{AG}=$ acides gras $; \mathrm{BHB}=\beta$-hydroxybutyrate $; \mathrm{TG}=$ triglycérides $; \mathrm{t}=$ trans $; \mathrm{c}=\mathrm{cis}$

autres acides gras digérés dans l'intestin grêle. L'acide propionique, le glucose, le trans 10 C18:1 et le trans 10 , cis $_{12}$ CLA n'agiraient pas directement en tant que précurseurs, mais indirectement soit sur la fourniture des précurseurs à chaîne carbonée longue (AGNE ou triglycérides circulants) soit sur la synthèse «de novo» (figure 1). Toutefois, si l'effet de ces nutriments est aujourd'hui démontré, leurs effets sur les variations du taux butyreux ne sont pas quantifiés. L'objectif de ce papier est de décrire les lois de réponse du taux butyreux et du rapport taux protéique/taux butyreux à des apports croissants des premiers 6 nutriments [les lois concernant les autres acides gras ayant été données par (Chilliard et al 1993)] et de rappeler l'état des connaissances sur les mécanismes de régulation impliqués dans les effets de ces nutriments. La connaissance de ces lois de réponses est une première étape pour envisager la construction de recommandations alimentaires permettant de mieux maîtriser la production de matière grasse.

\section{1 / Historique des théories avancées sur les nutriments jouant sur les variations importantes de taux buty- reux}

Les régimes à forte proportion de concentrés sont riches en glucides qui diminuent la proportion d'acide acé- tique et butyrique et augmentent la proportion de l'acide propionique dans le rumen et/ou celle du glucose dans l'intestin grêle selon leur dégradabilité dans le rumen (Sauvant 1997). Ces nutriments ont été proposés comme étant à l'origine des chutes de taux butyreux. Historiquement, l'origine du «low-fat milk syndrome» a été attribuée vers les années 50 à la diminution de la production d'acides acétique et butyrique dans le rumen, car ces acides ou leurs métabolites ( $\beta$-hydroxybutyrate) sont nécessaires à la synthèse «de novo» des acides gras du lait. Mais dans leur revue, Davis et Brown (1970) ont montré que la chute de taux butyreux observée avec les régimes riches en aliments concentrés n'était que partiellement compensée par l'apport exogène d'acide acétique ou butyrique. Un peu plus tard, l'augmentation de la production ruminale d'acide propionique a été proposée par McClymont et Wallance (1962) comme étant à l'origine du «low-fat milk syndrome». Ce fut la «théorie insulino-glucogénique» basée sur le fait que l'acide propionique dans le rumen ou le glucose dans le duodénum augmente la sécrétion d'insuline qui diminue la libération des acides gras longs du tissu adipeux. Bauman et Griinari concluent, dans leur revue de 2001, que l'augmentation de l'insulinémie (multipliée jusqu'à 4 fois) ne conduit qu'à des baisses modérées du taux butyreux. L'origine des chutes importantes de taux butyreux avec les régimes riches en concentrés a donc été recherchée ailleurs. Dans les années 1995-2000, l'origine des chutes de taux butyreux a donc plutôt été recherchée dans la production de trans C18:1 et plus particulièrement dans celle du trans ${ }_{10}$ C18:1 (Griinari et al 1998). Depuis les années 2000, l'attention s'est tournée vers d'autres produits de la dégradation des acides gras polyinsaturés dans le rumen, les acides linoléiques conjugués ou CLA, et plus particulièrement sur le trans $\mathrm{s}_{10}$, cis $_{12}$ CLA (Bauman et Griinari 2003).

\section{2 / Constitution des bases de données et analyses effectuées}

Tous ces nutriments provoquent des baisses plus ou moins marquées du taux butyreux, mais leur effet n'a jamais été quantifié et comparé sur une base commune. Pour ce faire, nous avons rassemblé les essais de la littérature dans lesquels ces nutriments avaient été apportés de façon contrôlée sous forme de perfusions ruminales (acide acétique, butyrique et propionique) ou postruminale (glucose, $\operatorname{trans}_{10} \mathrm{C} 18: 1$, trans $_{10}$, cis $_{12}$ CLA). Nous nous sommes limités à ce type d'essai de façon à quantifier le plus précisément possible les variations d'apport du nutriment ce qui n'est pas possible à partir d'essais d'alimentation qui induisent de nombreuses variations simultanées. Nous n'avons retenu que les essais dans lesquels les perfusions n'avaient pas entraîné de diminution importante de l'ingestion de matière sèche (moins de $5 \%$ ). Sauf mention spéciale, toutes les perfusions ont correspondu à un supplément d'énergie. Nous avons ensuite effectué une métaanalyse sur les données de ces essais selon une des méthodes décrites par Sauvant et al (2005). Une base de données par nutriment a été constituée.

Les caractéristiques principales des données contenues dans ces bases de données sont décrites dans le tableau 1. Pour chaque essai nous avons calculé la réponse (différence entre le lot supplémenté et le témoin) du taux butyreux, de la production de matières grasses et du rapport taux protéique sur taux butyreux en fonction des quantités de nutriments apportés en supplément. Les données ont été analysées par analyse de covariance suivant les modèles :

Réponse $=$ effet essai $+\mathrm{b}+\mathrm{a} \times$ Nutriment + erreur

lorsque les réponses étaient linéaires, ou

Réponse $=$ effet essai $+\mathrm{b}+\mathrm{a}_{0} \mathrm{x}$ Nutriment $+\mathrm{a}_{1} \mathrm{x}$ (Nutriment) $)^{2}+$ erreur 
Tableau 1. Descriptif des bases de données.

\begin{tabular}{|c|c|c|c|c|c|c|c|c|c|c|c|}
\hline \multirow[b]{2}{*}{ Nutriments } & \multirow[b]{2}{*}{ 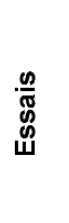 } & \multirow[b]{2}{*}{ 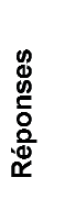 } & & \multicolumn{8}{|c|}{ Caractéristiques des lots Témoins } \\
\hline & & & $\begin{array}{l}\text { Apports } \\
(\mathrm{g} / \mathrm{j})\end{array}$ & $\begin{array}{l}\text { Fourrage } \\
\text { dominant }\end{array}$ & $\begin{array}{c}\text { MS } \\
\text { ingérée } \\
(g / j)\end{array}$ & $\begin{array}{c}\text { MAT } \\
(\% \text { MS) }\end{array}$ & 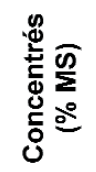 & Lait(g/j) & $\mathrm{TB}(\mathbf{g} / \mathbf{k g})$ & $\mathrm{TP}(\mathbf{g} / \mathbf{k g})$ & Références \\
\hline $\begin{array}{l}\text { Acide } \\
\text { acétique }\end{array}$ & 16 & 32 & $180-1428$ & $\begin{array}{c}\mathrm{F}(69 \%), \\
\text { EM (19\%), } \\
\text { P (13\%) }\end{array}$ & $\begin{array}{c}10,9 \\
(8,1-13,2)\end{array}$ & $\begin{array}{c}16,8 \\
(14,7-23,8)\end{array}$ & $\begin{array}{c}45 \\
(30-71)\end{array}$ & $\begin{array}{c}14,8 \\
(8,4-21)\end{array}$ & $\begin{array}{c}37,8 \\
(30,8-43,0)\end{array}$ & $\begin{array}{c}33,4 \\
(30,1-35,4)\end{array}$ & $\begin{array}{c}10232535 \\
363845\end{array}$ \\
\hline $\begin{array}{c}\text { Acide } \\
\text { butyrique }\end{array}$ & 12 & 27 & $252-1246$ & $\begin{array}{l}\text { F (66\%), } \\
\text { EH (33\%) }\end{array}$ & $\begin{array}{c}11,8 \\
(8,1-16,1)\end{array}$ & $\begin{array}{c}15,8 \\
(14,8-16,7)\end{array}$ & $\begin{array}{c}38 \\
(23-49)\end{array}$ & $\begin{array}{c}17,5 \\
(9,1-27,2)\end{array}$ & $\begin{array}{c}39,9 \\
(33,8-49,8)\end{array}$ & $\begin{array}{c}33,2 \\
(30,4-34,9)\end{array}$ & $\begin{array}{c}11122435 \\
\quad 3645\end{array}$ \\
\hline $\begin{array}{c}\text { Acide } \\
\text { propionique }\end{array}$ & 22 & 47 & $247-1584$ & $\begin{array}{l}\text { F (40\%), } \\
\text { EH }(40 \%), \\
\text { EM }(20 \%)\end{array}$ & $\begin{array}{c}15,9 \\
(8,1-21,6)\end{array}$ & $\begin{array}{c}16,0 \\
(13-18)\end{array}$ & $\begin{array}{c}42 \\
(36-59)\end{array}$ & $\begin{array}{c}19,9 \\
(8,4-36,9)\end{array}$ & $\begin{array}{c}40,0 \\
(30,8-47,2)\end{array}$ & $\begin{array}{c}30,6 \\
(24,3-34,1)\end{array}$ & $\begin{array}{c}5101314 \\
16182432 \\
35363740 \quad 45\end{array}$ \\
\hline Glucose & 23 & 56 & $250-2398$ & $\begin{array}{c}\text { EH }(54 \%), \\
\text { EM }(21 \%), \\
F(17 \%), \\
P(8 \%)\end{array}$ & $\begin{array}{c}16,7 \\
(5,9-22,5)\end{array}$ & $\begin{array}{c}16,0 \\
(13,9-24,8)\end{array}$ & $\begin{array}{c}41 \\
(0-63)\end{array}$ & $\begin{array}{c}24,9 \\
(4,2-36,9)\end{array}$ & $\begin{array}{c}40,1 \\
(28,5-54,8)\end{array}$ & $\begin{array}{c}30,8 \\
(26,4-36,5)\end{array}$ & $\begin{array}{l}89131516 \\
17181926 \\
27313233 \\
39404244 \\
\end{array}$ \\
\hline $\operatorname{trans}_{10} \mathrm{C} 18: 1$ & 2 & 6 & $7-97$ & $\begin{array}{l}\text { EM (50\%), } \\
\text { EH (50\%) }\end{array}$ & $\begin{array}{c}23,2 \\
(22,9-23,5)\end{array}$ & $\begin{array}{c}18,1 \\
(17,6-18-6)\end{array}$ & $\begin{array}{c}50 \\
(49-50)\end{array}$ & $\begin{array}{c}34,8 \\
(31,7-37,8)\end{array}$ & $\begin{array}{c}36,7 \\
(33,9-39,4)\end{array}$ & $\begin{array}{c}32,6 \\
(30,5-34,7)\end{array}$ & 3034 \\
\hline $\begin{array}{l}\operatorname{trans}_{10}, \\
\text { cis }_{12} \text { CLA }\end{array}$ & 13 & 36 & $1-46$ & $\begin{array}{c}\mathrm{F}(64 \%), \mathrm{EH}+ \\
\mathrm{EC}(36 \%)\end{array}$ & $\begin{array}{c}21,6 \\
(16,5-26,3) \\
\end{array}$ & $\begin{array}{c}16,4 \\
(13,7-20,4) \\
\end{array}$ & $\begin{array}{c}49 \\
(0-65) \\
\end{array}$ & $\begin{array}{c}26,4 \\
(19,7-35,2) \\
\end{array}$ & $\begin{array}{c}32,8 \\
(23,8-41,7) \\
\end{array}$ & $\begin{array}{c}29,9 \\
(26,5-33,2) \\
\end{array}$ & $\begin{array}{c}123467 \\
202122 \\
28294143 \\
\end{array}$ \\
\hline
\end{tabular}

$\mathrm{F}=$ foin $; \mathrm{EH}=$ ensilage d'herbe $; \mathrm{EM}=$ ensilage de maïs $; \mathrm{P}=$ paille $; \mathrm{EC}=$ ensilage de céréale $;(\text { plage de variation en italique })^{2}$

1 Baumgard et al 9 Frobish et Davis 17 Hurtaud et al (2000)

2 Baumgard et al 2001)

3 Baumgard et al (2002)

4 Bell et Kennelly (2003)

5 Chalmers et al (1980)

6 Chouinard et al 1999a)

7 Chouinard et al (1999b)

8 Clark et al (1977)

lorsque les réponses étaient curvilinéaires où Nutriment représente la quantité de nutriment apportée en supplément exprimée en kilogramme par jour. Cette unité a été conservée, car elle est plus facile à manipuler en pratique que des moles de nutriments ou des moles de carbones. Les données n'ont pas été pondérées par l'écart type résiduel de chaque essai, car la plupart des essais ont été réalisés en carré latin et les écarts types résiduels étaient comparables. Les interactions entre le pourcentage de concentrés et les covariables n'ont pas été prises en compte en raison d'une répartition très déséquilibrée de ce critère entre les différentes expérimentations. Les réponses présentées dans les figures ont été corrigées de l'effet essai et les réponses s'écartant de plus de 3 écarts types résiduels de la courbe moyenne ont été considérées comme aberrantes. Pour augmenter la lisibilité des figures, les différents «points zéro» corrigés de l'effet essai ont été représentés par un seul point : leur moyenne (zéro par définition biologique et statistique) pour les
(2000)

18 Hurtaud et Rulquin (1999)

19 Lemosquet et al (1997)

20 Loor et Herbein (1998)

21 Loor et Herbein (2003)

22 Mackle et al (2003)

23 McCullough et al (1969)

24 Miettinen (1996)

\begin{tabular}{|c|c|}
\hline & $\begin{array}{l}\text { Miller et Allen } \\
(1955)\end{array}$ \\
\hline & $\begin{array}{l}\text { Oldick et al } \\
\text { (1997) }\end{array}$ \\
\hline & $\begin{array}{l}\text { Ørskov et al } \\
\text { (1977) }\end{array}$ \\
\hline & $\begin{array}{l}\text { Perfield II et al } \\
\text { (2004) }\end{array}$ \\
\hline & $\begin{array}{l}\text { Peterson et al } \\
\text { (2002) }\end{array}$ \\
\hline & $\begin{array}{l}\text { Piperova et al } \\
\text { (2004) }\end{array}$ \\
\hline & $\begin{array}{l}\text { Rigout et al } \\
\text { (2002a) }\end{array}$ \\
\hline & $\begin{array}{l}\text { Rigout et al } \\
(2003)\end{array}$ \\
\hline
\end{tabular}

33 Rogers et al (1979)

34 Romo et al (2000)

35 Rook et al (1965)

36 Rook et Balch (1961)

37 van Soest et Allen (1959)

38 Stanley et Ueyama (1964)

39 Vanhatalo et Varvikko (2003a)

40 Vanhatalo et Varvikko (2003b)
41 de Veth et al (2004)

42 Vik-Mo et al (1974)

43 Viswanadha et al (2003)

44 Whitelaw et al (1986)

45 Wilson et al (1967) réponses et par l'ordonnée à l'origine pour les données exprimées en absolu (composition en acides gras, rapport taux protéique sur taux butyreux).

Pour chaque nutriment, nous présenterons les lois de réponses après avoir donné brièvement un ordre de grandeur de son flux et des variations possibles dans des rations courantes pour les vaches laitières, puis nous détaillerons les mécanismes de régulation mis en œuvre.

\section{3 / Acide acétique et acide butyrique}

\section{1 / Lois de réponse aux apports ruminaux d'acide acé- tique et butyrique}

La production d'Acides Gras Volatils $(\mathrm{AGV})$ dans le rumen n'est pas une donnée fréquente sur vache laitière car sa détermination nécessite l'utilisation de marqueurs isotopiques (radioactifs ou non) dont la mise en œuvre est très onéreuse sur ce type d'animaux. Chez une vache consommant $13-14 \mathrm{~kg}$ de $\mathrm{MS} / \mathrm{j}$ d'un régime à base d'herbe conservée complétée par 60 à $90 \%$ d'aliments concentrés, les productions d'acide acétique et butyrique varient de 2,9 à 3,4 et de 0,4 à $0,6 \mathrm{~kg} / \mathrm{j}$ respectivement (Sutton et al 2003). Pour une «vache type» ingérant $22 \mathrm{~kg}$ de $\mathrm{MS} / \mathrm{j}$ d'un régime classique à base d'ensilage de maïs équilibré avec du tourteau de soja (soit environ $12 \mathrm{~kg}$ de MO fermentescible (MOF)), les productions d'acide acétique et butyrique seraient de 3,7 et $0,87 \mathrm{~kg} / \mathrm{j}$ si l'on admet que les AGV produits représentent en moyenne $52 \%$ de la MOF (Sauvant et al 2006) et que le mélange des $\mathrm{AGV}$ du rumen contient en moyenne $60 \%$ d'acide acétique et $14 \%$ d'acide butyrique.

Le taux butyreux augmente significativement $(P<0,0001)$ respectivement $\mathrm{de}+2,20$ et $+7,33 \mathrm{~g} / \mathrm{kg}$ par kilogramme d'acide acétique et butyrique 
Figure 2. Réponse du taux butyreux à un supplément ruminal d'acide acétique ou butyrique.

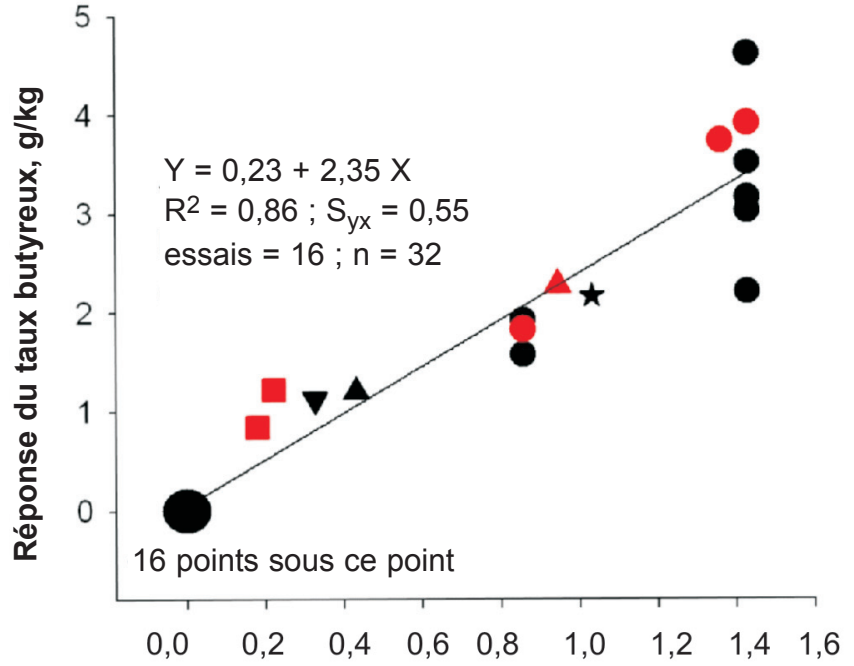

Perfusion ruminale d'acide acétique, $\mathrm{kg} / \mathrm{j}$

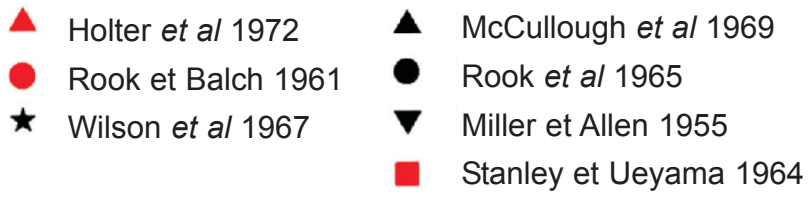

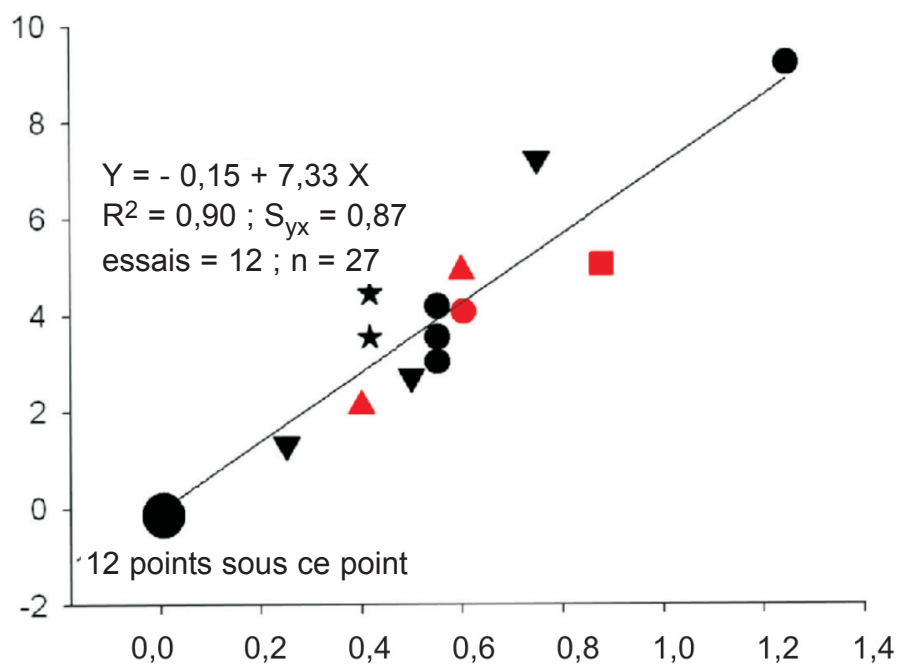

Perfusion ruminale d'acide butyrique, $\mathrm{kg} / \mathrm{j}$
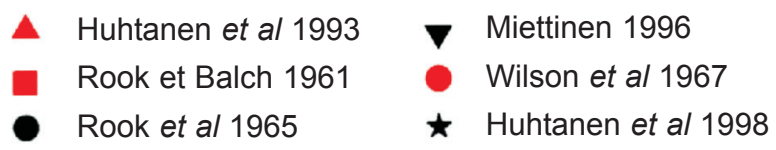

apporté en plus dans le rumen (figure 2). La production de matières grasses augmente significativement $(P<0,0001) \mathrm{de}+57 \mathrm{et}+104 \mathrm{~g} / \mathrm{j} \mathrm{par}$ kilogramme d'acide acétique ou butyrique ajouté. Le rapport taux protéique sur taux butyreux diminue significativement $(P<0,001)$ de $-5,3210^{-2}$ et $-13,310^{-2}$ unités par kilogramme d'acide acétique ou butyrique apporté en plus (figure 3).
3.2 / Mécanismes d'action de l'acide acétique et butyrique sur la synthèse des matières grasses

Le mécanisme d'action de ces deux acides gras volatils est lié au fait que ce sont eux qui fournissent les précurseurs (acétate et $\beta$-hydroxybutyrate) de la synthèse «de novo» des acides gras courts et moyens dans la glande mammaire (Moore et Christie 1981). Le fait que l'acide butyrique ait 2 fois plus d'effet (sur la base de la quantité de matières grasses) que l'acide acétique à même variation d'apport peut s'expliquer par le fait que c'est lui qui fournit l'amorce nécessaire à l'élongation des acides gras synthétisés dans la glande mammaire.

Figure 3. Relation entre le rapport taux protéique / taux butyreux et l'apport d'acide acétique ou butyrique.

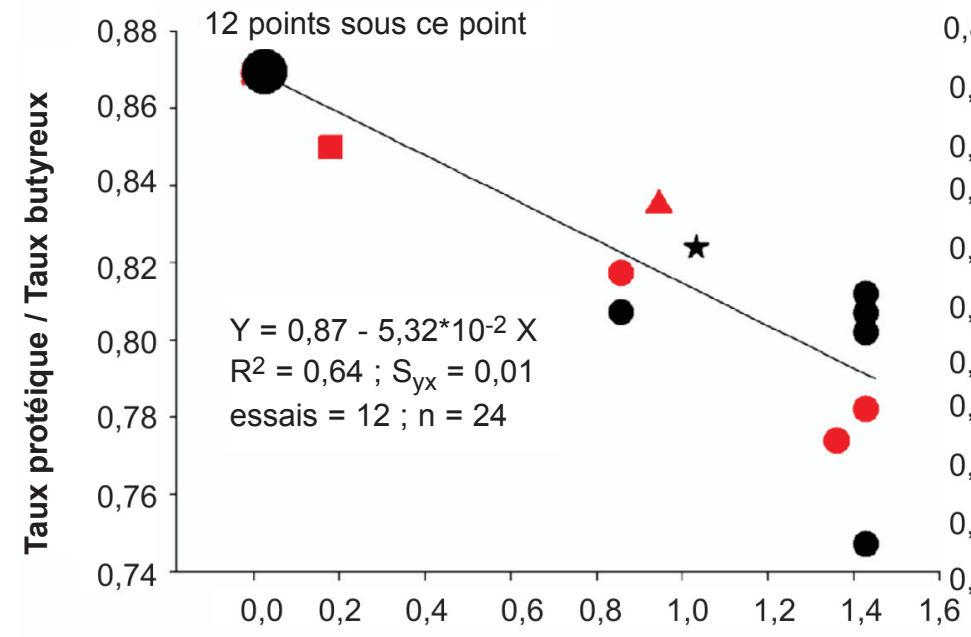

Perfusion ruminale d'acide acétique, $\mathrm{kg} / \mathrm{j}$

- Holter et al 1972

Stanley et Ueyama 1964

$\star \quad$ Wilson et al 1967

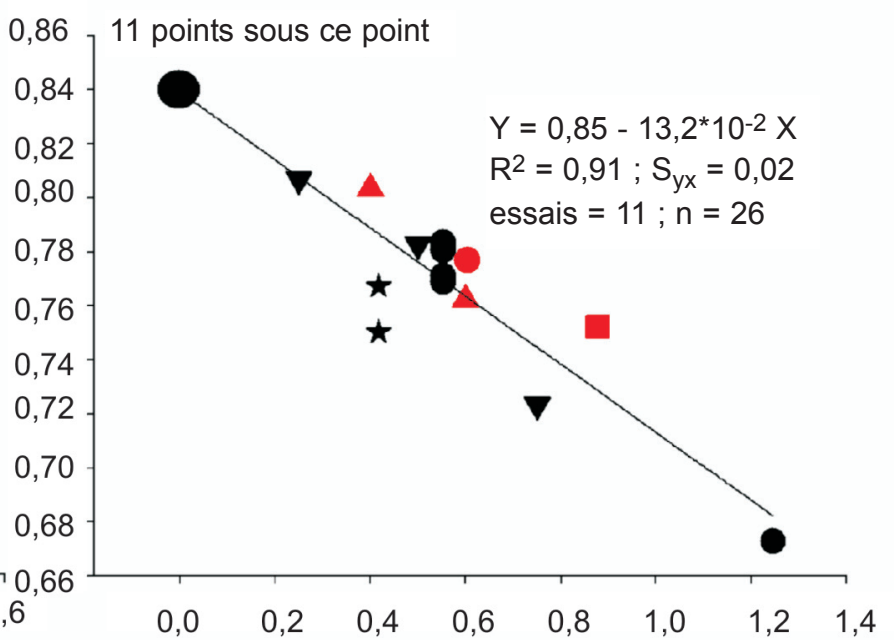

Perfusion ruminale d'acide butyrique, $\mathrm{kg} / \mathrm{j}$

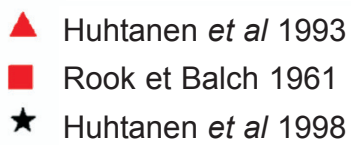

Miettinen 1996

- Wilson et al 1967

- Rook et al 1965 
Figure 4. Relation entre la chute de taux butyreux et un supplément ruminal d'acide propionique ou postruminal de glucose.

Perfusion ruminale d'acide propionique, $\mathrm{kg} / \mathrm{j}$

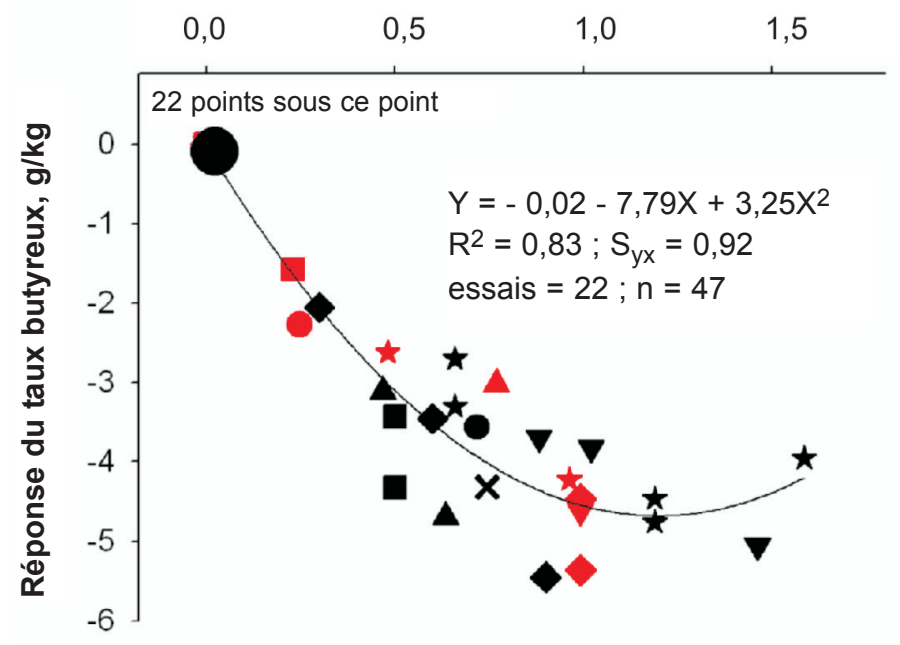

Perfusion postruminale de glucose, $\mathrm{kg} / \mathrm{j}$

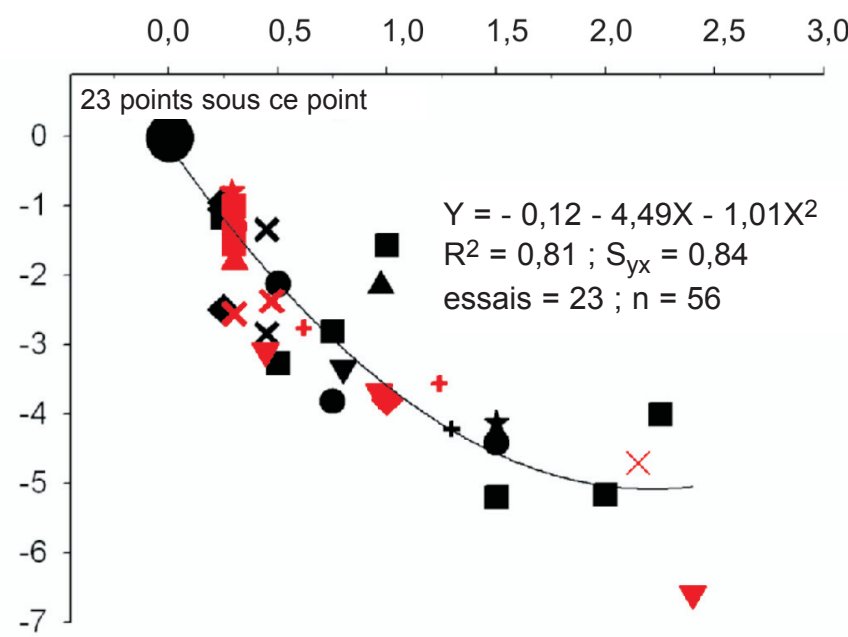

\section{4 / Acide propionique, glu- cose intestinal et amidon «by-pass»}

\section{1 / Lois de réponse aux apports ruminaux d'acide pro- pionique et postruminaux de glucose}

Toujours pour un niveau d'ingestion de 13 - $14 \mathrm{~kg}$ de $\mathrm{MS} / \mathrm{j}$, la production ruminale d'acide propionique varie de 1,2 à $2,6 \mathrm{~kg} / \mathrm{j}$ selon que le régime contient 60 ou $90 \%$ d'aliments concentrés (Sutton et al 2003). Pour la même «vache type» que précédemment, la production d'acide propionique serait de $1,25 \mathrm{~kg} / \mathrm{j}$ si le mélange des AGV du rumen contient en moyenne $20 \%$ d'acide propionique. Le flux postruminal d'amidon digestible (assimilable à du glucose) pourrait varier quant à lui de 0,4 à $4 \mathrm{~kg} / \mathrm{j}$ pour des rations à base d'herbe verte ou conservée supplémentées avec des concentrés ne comportant pas de céréales ou à base d'ensilage de maïs supplémentées avec $30 \%$ de maïs grain (Peyraud et Widyobroto 1994, Peyraud (non publié). Lorsque l'on joue sur l'alimen- tation, les flux ruminaux d'acide propionique et postruminaux d'amidon varient de façon générale en sens opposé (Sauvant 1997).

Les réponses du taux butyreux à un supplément d'acide propionique ou de glucose sont toujours négatives et le taux butyreux diminue significativement $(P<0,0001)$ suivant une loi curvilinéaire (figure 4). Il est possible de considérer que, pour des suppléments d'acide propionique ou de glucose allant respectivement jusqu'à $1 \mathrm{~kg} / \mathrm{j}$ ou 1,2 $\mathrm{kg} / \mathrm{j}$, la réponse du taux butyreux est linéaire et est égale à respectivement - 5,71 g/kg et - 2,99 g/kg par kilogramme d'acide propionique ou de glucose ajouté. La réponse de la production de matières grasses décroît $(P<0,001)$ respectivement de - 129 et - $66 \mathrm{~g} / \mathrm{j}$ par kilogramme d'acide propionique ou de glucose apporté. Le rapport taux protéique sur taux butyreux augmente significativement $(P<0,0001)$ de façon curvilinéaire (figure 5) pour les deux nutriments. Pour des apports inférieurs à 1 et $1,2 \mathrm{~kg} / \mathrm{j}$, il est possible de considérer que le rapport taux protéique sur taux butyreux augmente respectivement de $+13,710^{-2}$ et $+8,7310^{-2}$ unité par kilogramme d'acide propionique ou de glucose ajouté.

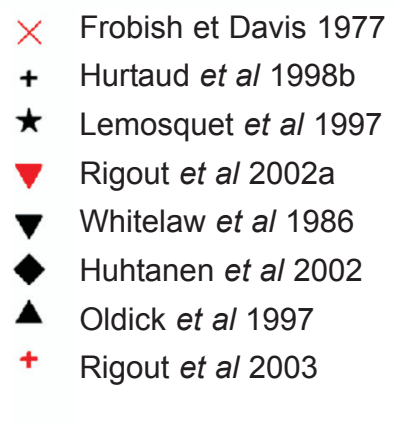

La perfusion d'acide propionique ne provoque pas de changement majeur de la composition en acides gras du lait si ce n'est une diminution linéaire significative $(P<0,001)$ des acides gras à chaîne courte (4 à 8 carbones) (figure 6), une augmentation des acides gras à chaîne impaire de carbone (Hurtaud et al 1993, 1998b, Hurtaud et Rulquin 1999, Miettinen 1996, Rigout et al 2003). Par contre, les perfusions de glucose entraînent une diminution curvilinéaire significative $(P<0,001)$, mais très légère (- 0,4 point par kilogramme de glucose ajouté) de la proportion des acides gras courts ( $\mathrm{C} 4$ à $\mathrm{C} 8)$, une augmentation des proportions d'acides gras synthétisés «de novo» (C10 à C15) et une réduction nette de la proportion des acides gras longs (C18) (figure 6) (Hurtaud et al 1998a, 1998b, 2000, Rigout et al 2002b, 2003).

$\mathrm{Au}$ niveau sanguin, les deux nutriments entraînent des modifications similaires qui signent un état anabolique du tissu adipeux. Les perfusions d'acide propionique et de glucose provoquent des baisses des teneurs plasmatiques en précurseurs des acides gras courts (acétate et $\beta$-hydroxybutyrate) et des acides gras longs (AGNE et triglycérides). Les diminutions d'acétate et 
Figure 5. Relation entre le rapport taux protéique / taux butyreux et l'apport ruminal d'acide propionique.

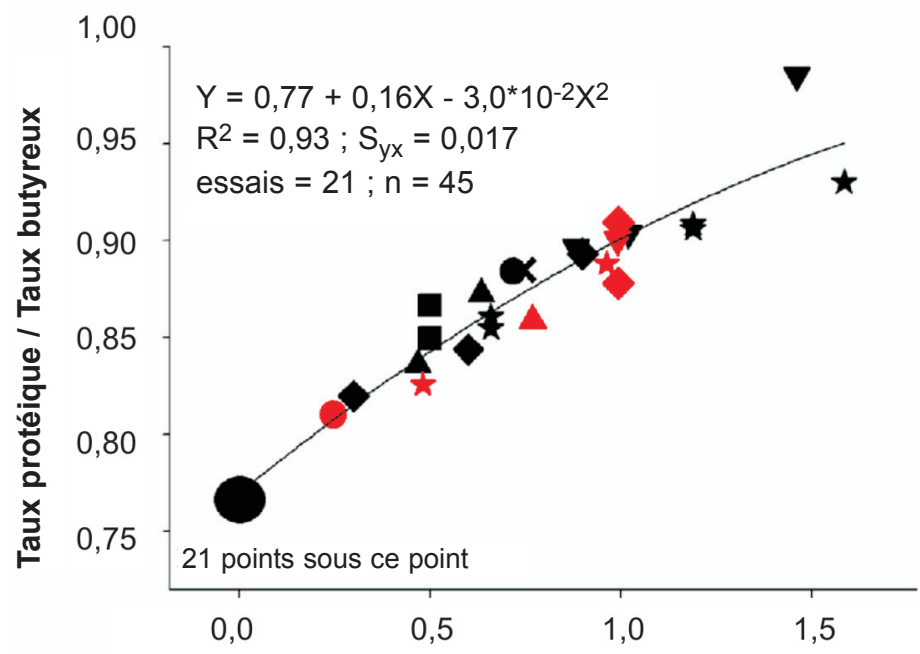

Perfusion ruminale d'acide propionique, $\mathrm{kg} / \mathrm{j}$

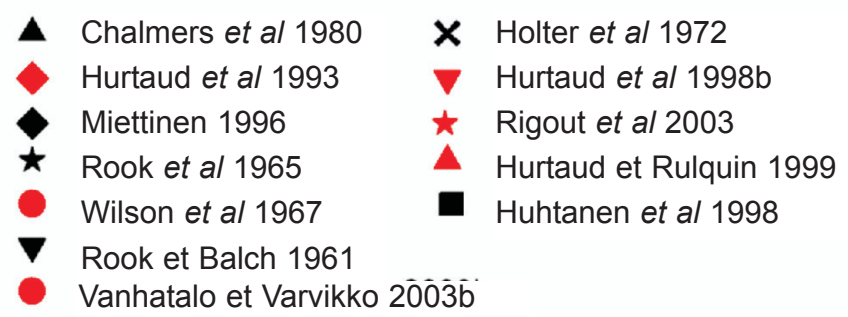

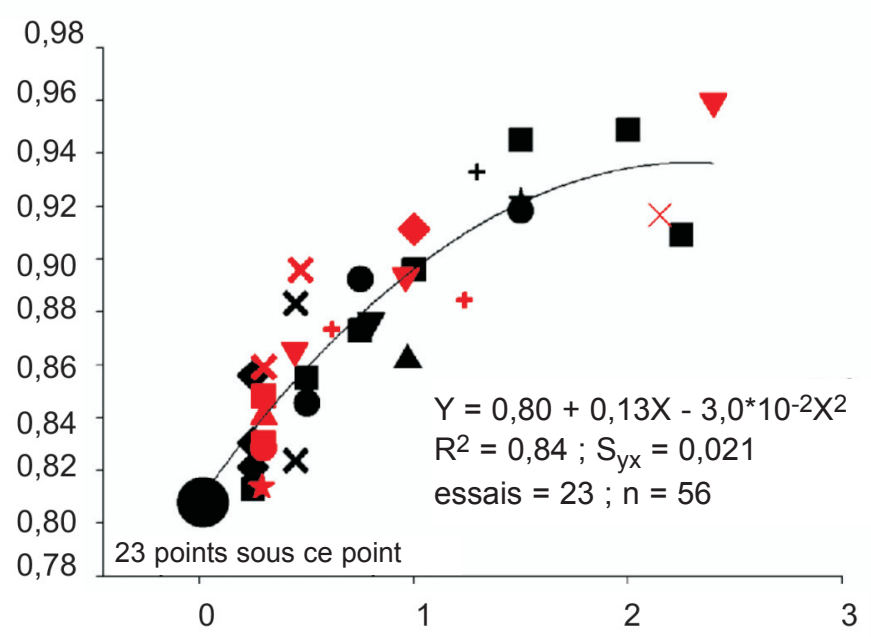

Perfusion postruminale de glucose, $\mathrm{kg} / \mathrm{j}$

× Clark et al 1977

- Hurtaud et al 1998a

Hurtaud et al 2000

- Orskov et al 1977

$\star \quad$ Rogers et al 1979

× Vik-Mo et al 1974

Hurtaud et Rulquin 1999

Frobish et Davis 1977

Vanhatalo et Varvikko 2003a

Vanhatalo et Varvikko 2003b'

Figure 6. Relation entre la composition en acides gras du lait et l'apport ruminal d'un supplément d'acide propionique ou postruminal de glucose.

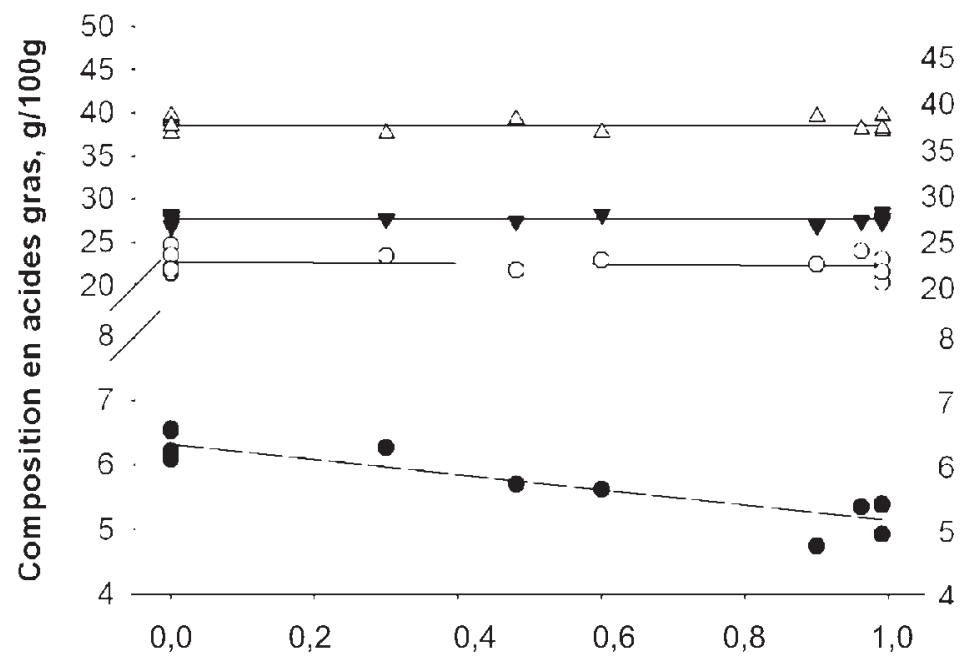

Perfusion ruminale d'acide propionique, $\mathrm{kg} / \mathrm{j}$

$$
\text { - } \quad \text { ¿C4 à C8 C } \quad \text { ¿C10 à C15 }
$$

(Hurtaud et al 1993. Hurtaud et al 1998b. Hurtaud et Rulquin 1999. Miettinen 1996. Rigout et al 2003)

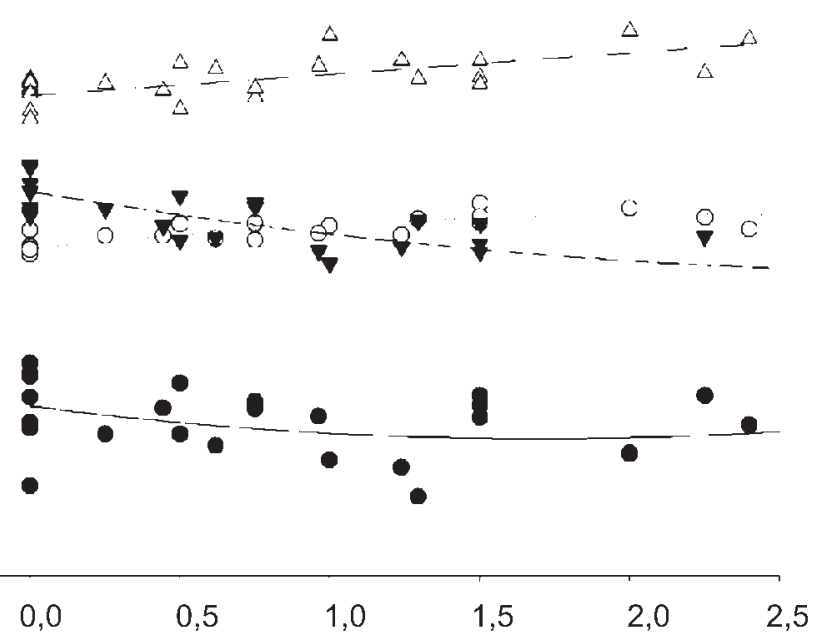

Perfusion postruminale de glucose, $\mathrm{kg} / \mathrm{j}$

$\triangle \quad \mathrm{CC} 16 \quad \checkmark \quad \mathrm{CC} 18$

(Hurtaud et al 1998a. Hurtaud et al 1998b. Hurtaud et al 2000. Rigout et al 2002b. Rigout et al 2003) 
de $\beta$-hydroxybutyrate sont du même ordre de grandeur pour les deux nutriments (- 15 à - $44 \%$ pour l'acétate -29 à - $63 \%$ pour le $\beta$-hydroxybutyrate). Par contre, le glucose provoque une baisse des AGNE et des triglycérides plus importante (- 4 à - $78 \%$ et - 14 à - $39 \%$ ) que celle enregistrée avec l'acide propionique (-2 à - $25 \%$ et - 3 à - $13 \%$ ) (Hurtaud et al 1998a, 1998b, 2000, Hurtaud et Rulquin 1999, Rigout et al 2002a, 2003).

Les effets de perfusions postruminales d'amidon sont beaucoup moins concordants que ceux de glucose, le produit final de la digestion de l'amidon. Reynolds et al (2001) ont rapporté une baisse du taux butyreux de - 2,3 g/kg en perfusant $0,7 \mathrm{~kg} / \mathrm{j}$ d'amidon de maïs dans le duodénum. La chute du taux butyreux n'a pas été plus marquée avec des doses supérieures sans doute parce que l'amidon supplémentaire a été fermenté dans le gros intestin et n'a pas fourni de glucose comme le suggère la diminution du $\mathrm{pH}$ des fèces (Reynolds et al 2001). La perfusion postruminale de $1 \mathrm{~kg} / \mathrm{j}$ d'amidon de blé partiellement hydrolysé a diminué le taux butyreux (- $3 \mathrm{~g} / \mathrm{kg})$ (Hurtaud et Rulquin 1999). De plus, les modifications de la composition en acides gras du lait induite par cette perfusion sont similaires à celles provoquées par une perfusion isoénergétique de glucose. Cependant, d'autres essais n'ont pas mis en évidence de diminution du taux butyreux lors de perfusion postruminale de $0,27 \mathrm{~kg} / \mathrm{j}$ d'amidon d'orge (Vanhatalo et Varvikko 2003b) ou de $1,5 \mathrm{~kg} / \mathrm{j}$ d'amidon partiellement hydrolysé (Knowlton et al 1998).

\section{2 / Mécanismes d'action de l'acide propionique et du gluco- se sur la synthèse des matières grasses}

Les diminutions du taux butyreux observées avec les perfusions d'acide propionique ou de glucose ont longtemps été attribuées à une moindre mobilisation des acides gras longs sous l'effet d'une stimulation de la sécrétion d'insuline. Selon les expériences, une légère augmentation (niveau de base multiplié par 1,2 à 1,5) significative de l'insuline plasmatique est observée (Frobish et Davis 1977, Hurtaud et al 2000, Lemosquet et al 1997), mais pas toujours (Frobish et Davis 1977, Hurtaud et al 1998a, Hurtaud et Rulquin 1999, Lemosquet et al 2004) lors des perfusions de glucose ou d'acide propionique. La réalisation de clamps hyperinsulinémiques euglycémiques pendant lesquels le niveau de base de l'insuline est multiplié par 4 a conduit à des réductions de l'ordre de $-2,9$ à $-5 \mathrm{~g} / \mathrm{kg}$ du taux butyreux (Bauman et Griinari 2003) démontrant que l'insuline n'était pas seule à l'origine des fortes chutes de taux butyreux observées dans les cas de «low-fat milk syndrome».

Le mécanisme par lequel l'acide propionique exerce son effet sur la synthèse des matières grasses reste inconnu, mais d'après les effets sur la composition en acides gras du lait (voir ci-dessus), il semble différent de celui impliqué pour le glucose. Pour le glucose, Lemosquet et al (1997) suggèrent que l'augmentation des disponibilités en glucose, en augmentant la fourniture de glycérol, favorise l'estérification des acides gras au niveau du tissu adipeux réduisant par conséquent la lipomobilisation. En effet, les disponibilités en glucose augmentent, car les perfusions postruminales de glucose entraînent une augmentation de la glycémie $(+2$ à $+17 \%$ ) qui n'est pas toujours significative, mais qui est toujours présente (Clark et al 1977, Frobish et Davis 1977, Lemosquet et al 1997, 2004, Hurtaud et al 1998a, 2000, Hurtaud et Rulquin 1999, Huhtanen et al 2002, Rigout et al 2002b). L'augmentation de la synthèse des acides gras «de novo» provient d'une diminution du prélèvement mammaire des acides gras longs qui inhibent l'acétyl CoA carboxylase (Hansen et Knudsen 1987, Palmquist et al 1993) et d'une plus grande utilisation intra-mammaire du glucose pour produire du NADPH (Rigout et al 2002a).

\section{5 /Acides gras $\operatorname{trans}_{10}$ C18:1 et $\operatorname{trans}_{10}, \operatorname{cis}_{12}$ CLA}

\section{1 / Lois de réponses à des apports intestinaux de $\operatorname{trans}_{10}$ C18:1 et $\operatorname{trans}_{10}, \operatorname{cis}_{12}$ CLA}

Dès 1965, Storry et Rook ont montré que l'ingestion de régimes riches en aliments concentrés par les vaches laitières se traduisait par la production de trans C18:1 dans le lait. Ceci a été confirmé par Griinari et al (1998), qui ont montré sur 17 essais que la réduction de la synthèse de matières grasses du lait est linéairement liée à la concentration en trans C18:1 dans le lait. Avec l'amélioration des techniques de séparation chromatographique, Griinari et al proposent dès 1998 que le trans 10
C18:1 soit plus particulièrement mis en cause dans les chutes de taux butyreux. Cette hypothèse est confortée par la bonne relation qui existe entre la proportion de trans $_{10} \mathrm{C} 18: 1$ retrouvée dans le lait et la chute de la sécrétion de matières grasses (Chilliard et al 2003, Loor et al 2005). A la même époque, des perfusions postruminales de mélanges de CLA, ont permis de démontrer que les CLA, étaient de puissants inhibiteurs de la sécrétion des matières grasses dans le lait (Loor et Herbein 1998). L'utilisation de CLA relativement purs a permis d'identifier le $\operatorname{trans}_{10}, \operatorname{cis}_{12}$ CLA comme étant à l'origine de la réduction de la synthèse des matières grasses du lait (Baumgard et al 2000, 2002, Loor et Herbein 2003).

Chez une vache ingérant $20 \mathrm{~kg}$ de $\mathrm{MS} / \mathrm{j}$, le flux duodénal peut varier de 2 à $51 \mathrm{~g} / \mathrm{j}$ pour le trans $10 \mathrm{C} 18: 1$ et de 70 à $100 \mathrm{mg} / \mathrm{j}$ pour le trans 10, cis $_{12}$ CLA suivant la richesse du régime en aliments concentrés et en acides gras insaturés (Loor et al 2004).

L'essai d'apport croissant dans la ration d'un mélange de sel de calcium de trans C18:1 de Piperova et al (2004) et celui de perfusion de Romo et al (2000) sont les seuls essais qui permettent de mettre en relation la réponse du taux butyreux avec le supplément postruminal de trans 10 C18:1. Afin de raisonner sur la même base d'apport de trans $_{10}$ C18:1 dans l'intestin, nous avons admis que le taux de protection de cet acide gras distribué sous forme de sels de calcium dans l'essai de Piperova et al (Piperova et al 2004) était de $44 \%$ (taux découlant de la comparaison des réponses obtenues avec les sels de calcium de trans ${ }_{10}$, cis $_{12}$ CLA avec celles obtenues par perfusion postruminale du produit pur (Rulquin non publié).

Le taux butyreux chute respectivement de façon linéaire $(P<0,01)$ et curvilinéaire $(P<0,0001)$ avec l'augmentation des doses de trans ${ }_{10}$ C18:1 et de $\operatorname{trans}_{10}$, cis ${ }_{12}$ CLA perfusées (figure 7). Il faut signaler que les doses les plus élevées représentent 2 fois le flux normal pour le trans ${ }_{10} \mathrm{C} 18: 1$ et plus de 200 fois pour le trans 10 , cis $_{12}$ CLA. Dans la zone où la réponse est linéaire $(0-100 \mathrm{~g} / \mathrm{j}$ pour le trans 10 $\mathrm{C} 18: 1$ et $0-10 \mathrm{~g} / \mathrm{j}$ pour le trans $10, \operatorname{cis}_{12}$ CLA), la chute serait de respectivement - $87 \mathrm{~g} / \mathrm{kg}$ et - $1467 \mathrm{~g} / \mathrm{kg}$ par $\mathrm{kg}$ de trans $_{10} \mathrm{C} 18: 1$ et de trans 10, cis $_{12}$ CLA ajouté. Il faut toutefois signaler que la régression pour le trans ${ }_{10}$ C18:1 
Figure 7. Relation entre le supplément postruminal de trans ${ }_{10}$ C18:1 ou de trans ${ }_{10}$, cis $s_{12}$ CLA et la réponse du taux butyreux.

Perfusion postruminale de trans ${ }_{10} \mathrm{C} 18: 1, \mathrm{~kg} / \mathrm{j} \quad$ Perfusion postruminale de trans ${ }_{10} \mathrm{cis}_{12} \mathrm{CLA}, \mathrm{kg} / \mathrm{j}$

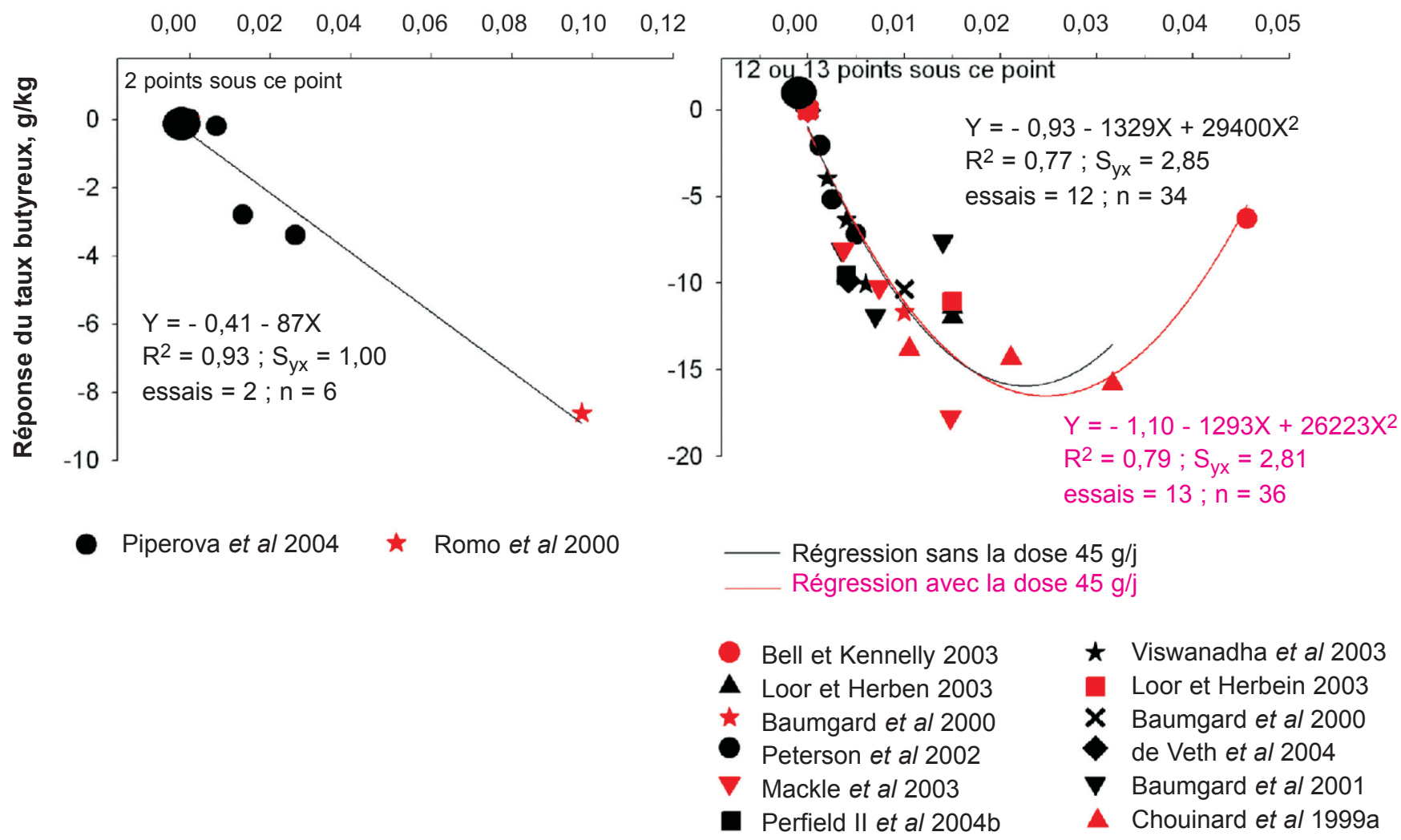

Figure 8. Relation entre le supplément postruminal de trans ${ }_{10}$, cis 12 CLA et la réponse du rapport taux protéique / taux butyreux.

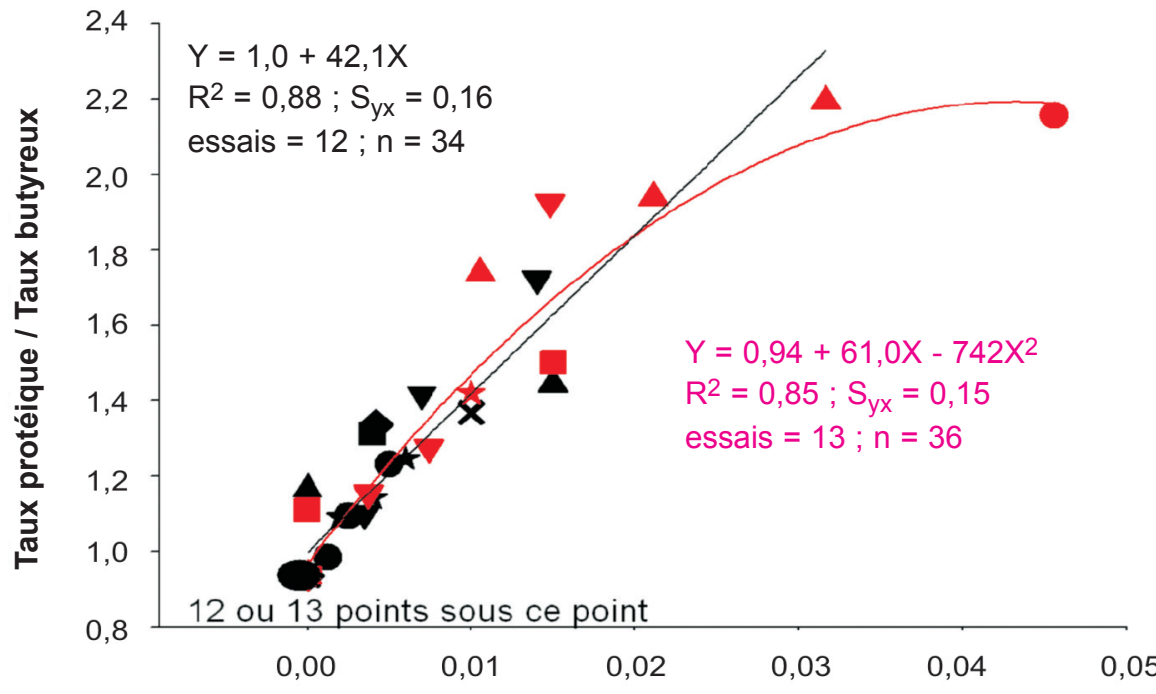

Perfusion postruminale de trans $_{10}$ cis $_{12} \mathrm{CLA}, \mathrm{kg} / \mathrm{j}$

Régression sans la dose $45 \mathrm{~g} / \mathrm{j}$

Régression avec la dose $45 \mathrm{~g} / \mathrm{j}$

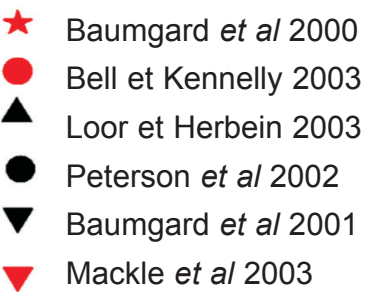

X Baumgard et al 2002

Loor et Herbein 1998

- Perfield II et al 2004b

$\star$ Viswanadha et al 2003

- Chouinard et al 1999a

de Veth et al 2004 est fortement influencée par la dose élevée perfusée dans l'essai de Romo et al (2000) (figure 7). La production de matières grasses chute aussi de façon linéaire $(P<0,05 ;-2257 \mathrm{~g} / \mathrm{j}$ par $\mathrm{kg})$ pour le trans $\mathrm{s}_{10} \mathrm{C} 18: 1$ et curvilinéaire avec un maximum de $-450 \mathrm{~g} / \mathrm{j}$ pour un supplément de $25 \mathrm{~g} / \mathrm{j}$ de $\operatorname{trans}_{10}$, cis $_{12}$ CLA. Le rapport taux protéique sur taux butyreux n'est pas significativement modifié par les perfusions de trans $_{10} \mathrm{C} 18: 1$ et augmente significativement $(P<0,0002)$ et de façon curvilinéaire pour le trans 10 , $\operatorname{cis}_{12}$ CLA (figure 8). Dans la zone allant de 0 à $10 \mathrm{~g} / \mathrm{j}$, il est possible de considérer que le rapport taux protéique sur taux butyreux s'accroîtrait de $+588910^{-2}$ unité par kg de trans 10 , $\operatorname{cis}_{12}$ CLA.

La comparaison des effets sur la composition en acides gras du lait provoqués par des perfusions postruminales de C18:1 cis ou trans a montré que la réduction du taux butyreux obtenue avec les trans était liée à la réduction de la synthèse «de novo» mammaire des acides gras (Gaynor et al 1994). L'apport postruminal de trans 10 , cis $_{12}$ CLA diminue linéairement la proportion d'acides gras synthétisés «de novo» $(\mathrm{C} 4$ à $\mathrm{C} 8, \mathrm{C} 10$ à $\mathrm{C} 15$ et une partie des C16) dans la mamelle et par conséquent accroît la proportion d'aci- 
Figure 9. Evolution de la composition en acides gras du lait en fonction de la dose de trans $_{10}$, cis ${ }_{12}$ CLA perfusée postruminalement.

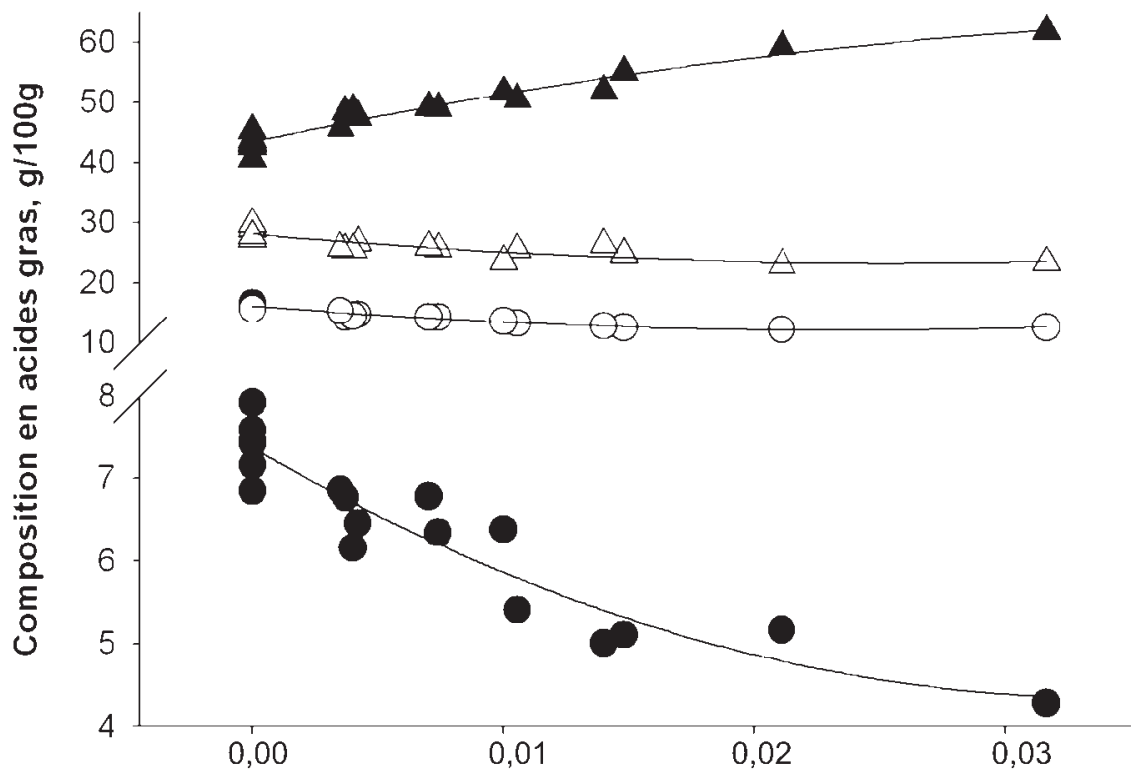

Perfusion postruminale de trans 10 , cis 12 CLA, kg/j

- ¿C4 à C8 $\bigcirc \quad$ IC10 à C15 $\triangle \quad$ IC16 $\Delta \quad \check{C} 18$

(Baumgard et a/ 2000. Baumgard et a/ 2001. Chouinard et al 1999a Mackle et al 2003. Perfield. II et a/ 2004. de Veth et a/ 2004)

des gras prélevés directement dans la circulation sanguine (somme des C18) (figure 9).

\section{2 / Mécanismes d'action des deux acides gras sur la synthèse des matières grasses}

Il est démontré que les isomères trans sont moins rapidement estérifiés en triglycérides par les cellules mammaires que les isomères cis (Askew et al 1971). Cela ne pourrait cependant pas expliquer une diminution sélective des acides gras synthétisés «de novo». L'effet du trans $10, \operatorname{cis}_{12}$ CLA semble se situer au niveau mammaire en réduisant la synthèse «de novo» et la désaturation (Bauman et Griinari 2003, Chouinard et al 1999a, Loor et Herbein 1998, 2003). La diminution des synthèses «de novo» est due à une diminution de l'activité de toutes les enzymes lipogéniques mammaires qui est liée à une inhibition de l'expression de leur gène (Ahnadi et al 2002, Peterson et al 2003, Piperova et al 2000).

Il semble peu vraisemblable que le mécanisme d'action du trans ${ }_{10} \mathrm{C} 18: 1$ passe par une transformation dans la mamelle des trans $_{10} \mathrm{C} 18: 1$ en trans 10 , $\operatorname{cis}_{12}$ C18:2 comme cela a été observé

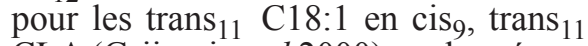
CLA (Griinari et al 2000) car la présence de la désaturase qui pourrait en être responsable n'a pas encore été détectée. Dans l'état actuel des connaissances, il reste donc difficile d'expliquer l'effet observé du trans $_{10} \mathrm{C} 18: 1$ sur le taux butyreux.

\section{6 / Efficacité comparée des différents nutriments}

\section{1 / Comparaison des effets des différents nutriments}

Le choix du moyen nutritionnel utilisé pour faire baisser le taux butyreux dépend de son efficacité et des objectifs poursuivis en terme de composition en acides gras du lait et de sa réalisation pratique. Dans la zone où les réponses sont linéaires, l'efficacité entre les différents nutriments pour moduler le taux butyreux est très différente (tableau 2). Pour réduire le taux butyreux, l'efficacité la plus élevée est obtenue avec le trans $10, \operatorname{cis}_{12}$ CLA (490 fois celle du glucose) et loin derrière avec le trans ${ }_{10} \mathrm{C} 18: 1$ (29 fois celle du glucose). Toutefois, ces diffé- rences d'efficacité sont un peu moins importantes lorsque l'efficacité est exprimée par rapport aux UFL apportées par les différents nutriments (tableau 2). Le classement entre nutriments n'est pas modifié, mais les écarts d'efficacité entre nutriments restent d'un facteur 100. La réalisation pratique en apportant des formes pures est plus ou moins aisée suivant les produits. En effet, il existe des formes protégées pour les acides gras trans et les CLA et l'acide propionique peut être apporté sous forme de sels. Par contre, pour le glucose il faudrait un procédé de protection qui n'existe pas encore. Les flux d'amidon non dégradés dans le rumen étant de mieux en mieux connus (Sauvant et al 2004), il reste à mieux préciser dans quelle mesure ces amidons sont des sources de glucose chez la vache et affectent la production de matières grasses. Il faut aussi rappeler que les effets sur la composition en acides gras du lait sont différents entre les nutriments démontrant par là que les mécanismes mis en jeu et les implications en terme de valeur nutritionnelle des laits sont différents (tableau 2). Ceci permet de supposer que les effets peuvent être additifs, mais il reste à le vérifier.

D'autres solutions que des apports de nutriments peuvent être envisagées. Ainsi, l'inoculation du rumen avec des bactéries propioniques a permis de réduire le taux butyreux de $5 \mathrm{~g} / \mathrm{kg}$ (Stein et al 2006). Il pourrait être aussi envisagé de réduire les fermentations butyriques en jouant sur le développement de la flore butyrique dans le rumen ou de la production d'acétate à l'aide par exemple sodium disulfite (Alhassan et al 1969). En attendant les progrès de la génétique, les formes de $\operatorname{trans}_{10}, \operatorname{cis}_{12}$ CLA ou de $\operatorname{trans}_{10}$ C18:1 protégées restent cependant, techniquement parlant, les moyens les plus prometteurs pour faire baisser le taux butyreux, car l'utilisation des sels d'acide propionique est limitée par les effets négatifs qu'a ce nutriment à fortes doses sur l'appétit. Cependant, l'ajout d'acides gras trans exogènes (trans $10, \operatorname{cis}_{12}$ CLA ou trans 10 $\mathrm{C} 18: 1)$ à la ration des vaches laitières pourrait être limité pour des raisons de précautions sanitaires. En effet, il n'est pas encore démontré que ces acides gras ne présenteraient pas les mêmes risques (cancérigènes) pour la santé humaine que les autres acides gras trans des graisses végétales hydrogénées (Pfeuffer et Schrezenmeir 2006). 
Tableau 2. Comparaison de l'efficacité des effets sur la composition en acides gras du lait et de la mise en œuvre pratique d'apport de nutriments purs.

\begin{tabular}{|c|c|c|c|c|c|}
\hline & \multicolumn{2}{|c|}{$\begin{array}{l}\text { Variation du taux } \\
\text { butyreux }\end{array}$} & \multirow{2}{*}{$\begin{array}{l}\text { Modifications } \\
\text { de la } \\
\text { composition } \\
\text { du lait }\end{array}$} & \multirow{2}{*}{$\begin{array}{c}\text { Apport } \\
\text { maximum } \\
\text { pour une } \\
\text { réponse } \\
\text { linéaire }\end{array}$} & \multirow{2}{*}{$\begin{array}{c}\begin{array}{c}\text { Réalisation } \\
\text { pratique }\end{array} \\
\text { Forme } \\
\text { apportée }\end{array}$} \\
\hline & $(\mathrm{g} / \mathrm{kg} / \mathrm{kg})$ & $(g / k g / U F L)$ & & & \\
\hline $\begin{array}{l}\text { Acide butyrique } \\
\text { ruminal }\end{array}$ & $+7,33$ & $+2,6$ & + de saturés & $1300(2,2)$ & $\begin{array}{c}\text { Sels de } \\
\mathrm{Na} \text { ou NH} \mathrm{NH}_{4}\end{array}$ \\
\hline $\begin{array}{c}\text { Acide acétique } \\
\text { ruminal }\end{array}$ & $+2,20$ & $+1,4$ & + de saturés & $1400(0,4)$ & $\begin{array}{l}\text { Sels de } \\
\mathrm{Na} \text { ou } \mathrm{NH}_{4}\end{array}$ \\
\hline $\begin{array}{c}\text { Glucose } \\
\text { postruminal }\end{array}$ & $-2,99$ & $-2,2$ & + de saturés & $1200(3,0)$ & $\begin{array}{l}\text { Impossible } \\
\text { pour l'instant }\end{array}$ \\
\hline $\begin{array}{l}\text { Acide propionique } \\
\text { ruminal }\end{array}$ & $-5,71$ & $-1,8$ & - de saturés & $1000(0,8)$ & $\begin{array}{l}\text { Sels de } \\
\mathrm{Na} \text { ou } \mathrm{NH}_{4}\end{array}$ \\
\hline $\begin{array}{l}\text { Trans }_{10} \text { C18:1 } \\
\text { post ruminal }\end{array}$ & -87 & $-18,8$ & - de saturés & $20(10,0)$ & Sels de $\mathrm{Ca}$ \\
\hline $\begin{array}{c}\text { Trans }_{10}, \text { cis }_{12} \text { CLA } \\
\text { postruminal }\end{array}$ & -1467 & $-244,9$ & - de saturés & $10(142,0)$ & $\begin{array}{l}\text { Sels de } \mathrm{Ca} \text {, } \\
\text { encapsulation }\end{array}$ \\
\hline
\end{tabular}

(entre parenthèses) $=$ nombre de fois le flux normal (supplément/flux normal).

\section{2 / Hiérarchisation du rôle des nutriments dans les chutes de taux butyreux observées avec l'accroissement du pourcentage de concentrés}

Les différents nutriments ont des effets très variables rapportés au kilodoivent être pondérés par les variations de quantités qui peuvent être mises en jeu lors de modification de la composition des rations. En jouant par le biais gramme ou à l'UFL mais leurs effets de l'alimentation (pourcentage et nature du concentré, finesse de broyage des aliments, fréquence des distributions d'aliments), il est possible de modifier les apports de l'ensemble des nutriments impliqués dans la régulation du taux butyreux, mais ceci de façon simultanée. Il est impossible de trouver un essai d'alimentation dans lequel le flux de tous ces nutriments a été mesuré. Nous avons juste trouvé 3 essais, réalisés sur des vaches laitières, ayant mesuré chacun un ou plusieurs flux des nutriments considérés et ayant un trai-
Tableau 3. Exemple de prédiction de la variation de taux butyreux et de la production de matières grasses provoquée par une augmentation de la part d'aliments concentrés dans la ration de $30 \%$.

\begin{tabular}{|c|c|c|c|c|c|}
\hline & \multirow{2}{*}{$\begin{array}{c}\text { Variation } \\
\text { de flux } \\
\text { observée }^{1} \\
\text { (kg/j) }\end{array}$} & \multicolumn{2}{|c|}{$\begin{array}{l}\text { Variations } \\
\text { prédites }\end{array}$} & \multicolumn{2}{|c|}{$\begin{array}{l}\text { Equations de prédiction } \\
\text { des variations }\end{array}$} \\
\hline & & $\begin{array}{c}\text { TB } \\
(\mathrm{g} / \mathrm{kg})\end{array}$ & $\begin{array}{c}\text { Mat. } \\
\text { grasses } \\
(\mathbf{g} / \mathbf{j})\end{array}$ & TB & Mat. grasses \\
\hline $\operatorname{trans}_{10}, \mathrm{cis}_{12} \mathrm{CLA}$ & 0,000015 & $-1,1$ & -18 & $\begin{array}{l}-1,1-1293 X \\
+26222 X^{2} \\
\end{array}$ & $\begin{array}{l}-18+33043 X \\
+610193 X^{2} \\
\end{array}$ \\
\hline $\operatorname{trans}_{10} \mathrm{C} 18: 1$ & 0,019 & $-2,1$ & -80 & $-0,41-87,3 X$ & $-37-2257 X$ \\
\hline Glucose & 0,07 & $-0,4$ & -5 & $\begin{array}{l}-0,12-4,49 X \\
-1,01 X^{2}\end{array}$ & $2-94 X+13 X^{2}$ \\
\hline C3 & 1,4 & $-4,6$ & -110 & $\begin{array}{l}-0,02-7,79 X \\
+3,25 X^{2} \\
\end{array}$ & $-3-145 X+49 X^{2}$ \\
\hline $\mathrm{C} 2$ & $-0,45$ & $-0,8$ & -22 & $0,23+2,2 X$ & $3+57 X$ \\
\hline C4 & $-0,15$ & $-1,2$ & -17 & $-0,15+7,33 X$ & $-1+104 X$ \\
\hline Variation prédite $^{2}$ & & $-10,2$ & -252 & & \\
\hline Variation observée $^{1}$ & & $-15,3$ & -196 & & \\
\hline$\%$ explication & & $\begin{array}{c}67 \\
111^{3}\end{array}$ & 128 & & \\
\hline
\end{tabular}

1 D'après les données de Loor et al (2004), Sutton et al (1980), Sutton et al (2003).

2 Variations calculées d'après les équations précédemment décrites.

3 Calculé par rapport à la chute de TB mesurée non imputable à l'effet dilution. tement alimentaire commun : une augmentation du pourcentage d'aliments concentrés de $30 \%$. A titre d'illustration, nous avons donc estimé les effets des modifications des flux de nutriments provoquées par cette augmentation du pourcentage de concentré sur les productions ruminales d'acides gras volatils, le flux duodénal d'amidon et les flux d'acides gras trans ${ }_{10} \mathrm{C} 18: 1$ et trans $_{10}, \operatorname{cis}_{12}$ CLA. en se basant respectivement sur les résultats de Sutton et al (2003, 1980) et Loor et al (2004).

Dans les essais de Sutton et al (1980, 2003) le pourcentage d'aliment concentré (à base d'orge) passait de 60 à $90 \%$, dans l'essai de Loor et al (2004) ce pourcentage passait de 30 à $60 \%$. Les variations de flux des 6 nutriments précédemment étudiés provoquées par l'augmentation du pourcentage d'aliment concentré sont données dans le tableau 3. D'après les équations que nous avons établies précédemment, ces variations de flux de nutriments pourraient expliquer une chute de taux butyreux de $4,6 \mathrm{~g} / \mathrm{kg}$ pour l'augmentation de la production d'acide propionique, de $2,1 \mathrm{~g} / \mathrm{kg}$ pour celle de trans 10 C18:1, de $1,1 \mathrm{~g} / \mathrm{kg}$ pour celle de trans $_{10}$, cis $_{12}$ CLA, de $1,2 \mathrm{~g} / \mathrm{kg}$ pour la diminution de la production d'acide butyrique, de $0,8 \mathrm{~g} / \mathrm{kg}$ pour la diminution de production d'acide acétique et de $0,4 \mathrm{~g} / \mathrm{kg}$ pour l'augmentation du flux d'amidon digéré dans l'intestin en supposant qu'il fournisse uniquement du glucose (tableau 3). En considérant les phénomènes comme additifs, la chute totale prévisible serait donc de $10,2 \mathrm{~g} / \mathrm{kg}$, ce qui correspond à $67 \%$ de la chute moyenne observée entre les trois essais qui ont servi à fournir les données de flux de nutriments. Le même calcul effectué sur la production de matières grasses conduit à une explication de $128 \%$ de la chute observée par la chute prédite. Les différences entre les résultats sur le taux et la production proviennent du fait qu'une partie de la chute du taux observée provient de la dilution consécutive à l'augmentation de production. Cette augmentation de production observée avec l'accroissement du pourcentage d'aliments concentrés qui ne serait pas explicable par les variations de flux de nutriments énergétiques pourrait provenir d'une augmentation du flux de protéines microbiennes consécutive à l'augmentation de la MOF. En prenant en compte le phénomène de dilution $(-6,1 \mathrm{~g} / \mathrm{kg})$ la part d'explication passe à $111 \%$ dans le cas du taux (tableau 3). L'écart entre la chute prédite et celle 
observée est dû au fait que les données de flux ne proviennent pas du même essai et/ou à la non-additivité des effets des nutriments apportés en mélange. Il peut aussi provenir du fait des cinétiques d'apports de nutriments différents entre des essais de perfusions (continu) et d'alimentation (fractionné). La valeur absolue de ces calculs importe peu, elle permet de montrer que la prise en compte de l'ensemble des nutriments jouant sur le taux butyreux est amplement suffisante pour expliquer la totalité de la variation du taux butyreux alors que la prise en compte d'un seul nutriment comme cela été fait jusqu'ici explique au mieux la moitié de la variation. Ceci permet aussi de montrer que chacune des théories successivement invoquées (voir précédemment) est en partie vraie, mais qu'aucune ne l'est totalement. Ce calcul permet de plus de relativiser le rôle de chaque nutriment eu égard aux variations de leurs flux respectifs. Dans notre exemple, la chute du taux butyreux proviendrait en premier (54\%) de l'augmentation de la production des précurseurs du glucose, ensuite de l'augmentation des flux postruminaux d'acides gras contenant du trans 10 (35\%), puis de la diminution de la production ruminale des précurseurs des acides gras courts $(22 \%)$. Le rôle du glucose, lorsque la céréale du concentré est du maïs est plus important, puisque l'augmentation du flux intestinal d'amidon digestible est alors de $560 \mathrm{~g} / \mathrm{j}$ (Sutton et al 1980). Il pourrait alors expliquer une chute du taux butyreux de - 2,6 g/kg, mais en contrepartie le rôle du propionate serait plus faible. Il est à noter que malgré une efficacité à faire chuter le taux butyreux très supérieure à celle des autres nutriments, le trans $_{10}$, cis $_{12}$ CLA ne jouerait, dans notre exemple, qu'un rôle modéré dans la baisse du taux butyreux. Lors d'une supplémentation en lipides insaturés du régime, son rôle ne semble pas plus important $(-1,2 \mathrm{~g} / \mathrm{kg})$ alors que celui $\mathrm{du}$ trans $_{10} \mathrm{C} 18: 1$ augmente $(-3,0 \mathrm{~g} / \mathrm{kg})$ en se basant sur les données de flux de Loor et al (2004).

Il apparaît donc possible de bâtir un système qui à partir des flux digestifs des différents nutriments prédirait à l'aide de ces équations les variations de taux et de production de matières grasses. Pour vérifier ce système, il faudrait être en mesure de mesurer le flux de tous ces nutriments simultanément. Ceci est malheureusement impossible, étant donné la lourdeur des mesures. Il faudra donc procéder indirectement en estimant les flux des nutriments à partir des caractéristiques physico-chimiques de la ration. En attendant un modèle mécaniste qui bute pour l'instant sur la prédiction de la composition en acides gras volatils du jus de rumen, il devrait être possible d'établir un modèle empirique additif dont les prévisions pourraient être ajustées aux mesures de production par régression. Pour cela nous disposons d'une base de données regroupant environ 600 essais dans lesquels la composition de la ration, le profil fermentaire du rumen et les productions ont été enregistrés. Les flux d'acides gras volatils pourront être estimés à partir de la MOF x 0,52 (Sauvant et al 2006) et du profil fermentaire, le flux intestinal de glucose peut être estimé à partir des quantités ingérées d'amidon et de la dégradabilité ruminale de l'amidon (Sauvant et al 2004) et des équations permettant de passer de la dégradabilité in situ à une digestibilité in vivo (Offner et Sauvant 2004), l'estimation des flux de trans $_{10}$ C18:1 et $\operatorname{trans}_{10}, \operatorname{cis}_{12}$ CLA à partir des caractéristiques de la ration est en cours de publication (Glasser et al sous presse) et (Schmidely et al sous presse).

\section{Conclusion}

Ce travail montre que l'amélioration des connaissances sur les réponses de l'animal au cours des cinquante dernières années permet d'espérer prédire les variations du taux butyreux en fonction de l'alimentation. Il faudra pour cela bâtir un modèle prenant en compte les 7 nutriments connus pour affecter la synthèse des matières grasses (acides acétique, butyrique, propionique produits dans le rumen, acides gras longs, trans $_{10}$ C18:1, $\operatorname{trans}_{10}$, cis ${ }_{12}$ CLA, glucose absorbés dans l'intestin grêle) au prorata des variations de leur flux digestif en fonction de l'équilibre des rations. Ce modèle, complémentaire au système UFL existant, préciserait la composition de ces UFL. Pour réaliser un tel modèle, il faut être capable de prédire le flux des différents nutriments à partir de la composition chimique de la ration, de la vitesse de dégradation des constituants et de la taille des particules, car ce sont des facteurs qui ont démontré leurs effets dans les pratiques d'alimentation. Ce travail devient une priorité compte tenu des enjeux autour de la matière grasse laitière, mais il ne peut être réalisé que par plusieurs équipes. Des travaux de ce genre sont entrepris à l'INRA de Theix, Paris et Rennes. Les verrous les plus importants à lever et qui nécessitent des approches expérimentales nous paraissent être aujourd'hui la prévision des flux d'acides gras volatils et les phénomènes d'hydrogénation de la matière grasse de la ration dans le rumen afin d'estimer les flux de trans $_{10} \mathrm{C} 18: 1$ et de trans $10, \operatorname{cis}_{12}$ CLA. Au niveau de la réponse de l'animal, il s'agira de vérifier par des essais de perfusion dans quelle mesure les effets des nutriments sont additifs et de compléter la courbe dose-réponse au trans $_{10} \mathrm{C} 18: 1$ qui semble avoir en pratique un effet plus important que le trans $_{10}, \operatorname{cis}_{12}$ CLA. Il faudra aussi valider les réponses sur le long terme sachant que les essais de perfusion utilisés dans cette synthèse étaient conduits sur des périodes excédant rarement plus de 3 semaines.

\section{Références}

Ahnadi C.E., Beswick N.S., Delbechi L., Kenelly J.J., Lacasse P., 2002. Addition of fish oil to diets for dairy cows. II. Effect on milk fat and gene expression of mammary lipogenic enzymes. J. Dairy Res., 69, 521-531.

Alhassan W.S., Krabill L.F., Satter L.D., 1969. Manipulation of the ruminal fermentation. I. Effect of sodium sulfite on bovine ruminal fatty acid concentration and milk composition. J. Dairy Sci., 52, 376-379.

Askew E.W., Emery R.S., Thomas J.W., 1971. Fatty acids specificity of glyceride synthesis by homogenates of bovine mammary tissue. Lipids, $6,777-782$.

Bauman D.E., Griinari J.M., 2001. Regulation and nutritional manipulation of milk fat: low-fat milk syndrome. Livest. Prod. Sci., 70, 15-29.

Bauman D.E., Griinari J.M., 2003. Nutritional regulation of milk fat synthesis. Ann. Rev. Nutr., 23, 203-227.

Baumgard L.H., Corl B.A., Dwyer D.A., Saebo A., Bauman D.E., 2000. Identifica- tion of the conjugated linoleic acid isomer that inhibits milk fat synthesis. A.J.P., 278, R179R184.

Baumgard L.H., Sangster J.K., Bauman D.E., 2001. Milk fat synthesis in dairy cows is progressively reduced by increasing supplemental

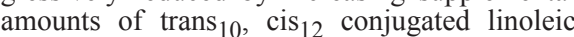
acid (CLA). J. Nutr., 131, 1764-1769.

Baumgard L.H., Matitashvili E., Corl B.A. Dwyer D.A., Bauman D.E., 2002. Trans 10 , cis $_{12}$ conjugated linoleic acid decreases lipogenic rates and expression of genes involved in milk 
lipid synthesis in dairy cows. J. Dairy Sci., 85 , 2155-2163.

Bell J.A., Kennelly J.J., 2003. Short communication: postruminal infusion of conjugated linoleic acids negatively impacts milk synthesis in Holstein cows. J. Dairy Sci., 86, 1321-1324.

Bonaïti B., 1985. Composition du lait et sélection laitière chez les bovins. Bull. Tech. C.R.Z.V. Theix, I.N.R.A., 59, 51-56.

Chalmers J.S., Thomas P.C., Chamberlain D.G., 1980. The effect of intraruminal infusions of propionic acid on milk composition in cows given silage diets. Proc. Nutr. Soc., 39, 27A.

Chilliard Y., Sauvant D., 1987. La sécrétion des constituants du lait. In : Le lait matière première de l'industrie laitière. INRA (Eds). INRACEPIL, Versailles, France, 13-26.

Chilliard Y., Doreau M., Gagliostro G., Elmeddah Y., 1993. Addition de lipides protégés (encapsulés ou savons de calcium) à la ration de vaches laitières. Effets sur les performances et la composition du lait. INRA Prod. Anim., 6, 139-150.

Chilliard Y., Ferlay A., Rouel J., Lamberet G., 2003. A review of nutritional and physiological factors affecting goat milk lipid synthesis and lipolysis. J. Dairy Sci., 86, 1751-1770.

Chouinard P.Y., Corneau L., Barbano D.M., Metzger L.E., Bauman D.E., 1999a. Conjugated linoleic acids alter milk fatty acid composition and inhibit milk fat secretion in dairy cows. J. Nutr., 129, 1579-1584

Chouinard P.Y., Corneau L., Sabo A., Bauman D.E., 1999b. Milk yield and composition during abomasal infusion of conjugated linoleic acids in dairy cows. J. Dairy Sci., 82, 2737-2745.

Clark J.H., Spires H.R., Derrig R.G., Bennink M.R., 1977. Milk production, nitrogen utilization and glucose synthesis in lactating cows infused postruminally with sodium caseinate and glucose. J. Nutr., 107, 631-644.

Coulon J.B., Chilliard Y., Rémond B., 1991. Effets du stade physiologique et de la saison sur la composition chimique du lait de vache et ses caractéristiques technologiques. INRA Prod. Anim., 4, 219-228.

Davis C.L., Brown R.E., 1970. Low-fat milk syndrome. In: Physiology of digestion and metabolism in the ruminant. A. T. Phillipson. Oriel Press, (Eds). Newcastle upon Tyne, England, 545-565.

de Veth M.J., Griinari J.M., Pfeiffer A.M., Bauman D.E., 2004. Effect of CLA on milk fat synthesis in dairy cows: comparison of inhibition by methyl esters and free fatty acids, and relationships among studies. Lipids, 39, 365-372.

Frobish R.A., Davis C.L., 1977. Effects of abomasal infusions of glucose and propionate on milk yield and composition. J. Dairy Sci., 60, 204-209.

Gaynor P.J., Erdman R.A., Teter B.B., Sampugna J., Capuco A.V., Waldo D.R., Hamosh M., 1994. Milk fat yield and composition during abomasal infusion of cis or trans octadecenoates in Holstein cows. J. Dairy Sci., 77, 157-165.

Glasser F., Schmidely P. , Sauvant D., Doreau M., 2007. Digestion of fatty acids in ruminants: a meta-analysis of flows and variation factors. 2 . C18 fatty acids. Animal, sous presse.

Griinari J.M., Dwyer D.A., McGuire M.A., Bauman D.E., Palmquist D.L., Nurmela K.V.V., 1998. Trans-octadecenoic acids and milk fat depression in lactating dairy cows. J. Dairy Sci., $81,1251-1261$
Griinari J.M., Corl B.A., Lacy S.H., Chouinard P.Y., Nurmela K.V.V., Bauman D.E., 2000. Conjugated linoleic acid is synthesized endogenously in lactating dairy cows by \{delta\}9-desaturase. J. Nutr., 130, 2285-2291.

Hansen H.O., Knudsen J., 1987. Effect of exogenous long-chain fatty acids on individual fatty acid synthesis by dispersed ruminant mammary cells. J. Dairy Sci., 70, 1350-1354.

Hoden A., Coulon J.B., 1991. Maîtrise de la composition du lait : influence des facteurs nutritionnels sur la quantité et les taux de matières grasses et protéiques. INRA Prod. Anim., 4, 361-367.

Holter J.B., Jones L.A., Colovos N.F., Urban W.E., 1972. Caloric value of acetate and propionate for lactating dairy cows. J. Dairy Sci., 55, 1757-1762.

Huhtanen P.J., Miettinen H., Ylinen M., 1993 Effect of increasing ruminal butyrate on milk and blood constituents in dairy cows fed a grass silage-based diet. J. Dairy Sci., 76, 1114-1124.

Huhtanen P.J., Blauwiekel R., Saastamoinen I., 1998. Effects of intraruminal infusions of propionate and butyrate with two different protein supplements on milk production and blood metabolites in dairy cows receiving grass silagebased diet. J. Sci. Fd Agric., 77, 213-222.

Huhtanen P., Vanhatalo A., Varvikko T., 2002. Effects of abomasal infusions of histidine, glucose, and leucine on milk production and plasma metabolites of dairy cows fed grass silage diets. J. Dairy Sci., 85, 204-216.

Hurtaud C., Rulquin H., 1999. Effet de la nature des nutriments énergétiques (acide propionique, glucose ou amidon) sur la production et la composition du lait chez les vaches laitières. Renc. Rech. Rum., 6, 103-106.

Hurtaud C., Rulquin H., Vérité R., 1993. Effect of infused volatile fatty acids and caseinate on milk composition and coagulation in dairy cows. J. Dairy Sci., 76, 3011-3020.

Hurtaud C., Rulquin H., Vérité R., 1998a. Effects of graded duodenal infusions of glucose on yield and composition of milk from dairy cows. 1. Diets based on corn silage. J. Dairy Sci., 81, 3239-3247.

Hurtaud C., Rulquin H., Vérité R., 1998b. Effects of level and type of energy source (volatile fatty acids or glucose) on milk yield, composition and coagulating properties in dairy cows. Reprod. Nutr. Dev., 38, 315-330.

Hurtaud C., Lemosquet S., Rulquin H., 2000. Effect of graded duodenal infusions of glucose on yield and composition of milk from dairy cows. 2. Diets based on grass silage. J. Dairy Sci., 83, 2952-2962.

Institut de l'Elevage, 2005. Taureaux français du 27 janvier 2005 et inter bull du 13 mai 2005. ://www.inst-elevage.asso.fr/html/ rubrique.php3?id_rubrique $=822 \& i d$ groupe $=6 \&$ id mot $=177 \& \overline{\mathrm{ie}}$ WEBFRA $=$ Y\&ie CORAI $\mathrm{N}=66 \&$ ie inter $=6 \& \mathrm{ie}$ page $=0$.

Journet M., Chilliard Y., 1985. Influence de l'alimentation sur la composition du lait. 1. Taux butyreux : facteurs généraux. Bull. Tech. C.R.Z.V. Theix, I.N.R.A., 60, 13-23.

Knowlton K.F., Dawson T.E., Glenn B.P., Huntington G.B., Erdman R.A., 1998. Glucose metabolism and milk yield of cows infused abomasally or ruminally with starch. J. Dairy Sci., 81,3248 .

Kucerova J., Lund M.S., Sorensen P., Sahana G., Guldbrandtsen B., Nielsen V.H., Thomsen B.,
Bendixen C., 2006. Multitrait quantitative trait loci mapping for milk production traits in Danish Holstein cattle. J. Dairy Sci., 89, 2245-2256.

Lemosquet S., Rideau N., Rulquin H., Faverdin P., Simon J., Vérité R., 1997. Effects of a duodenal glucose infusion on the relationship between plasma concentrations of glucose and insulin in dairy cows. J. Dairy Sci., 80, 2854 2865 .

Lemosquet S., Rigout S., Bach A., Rulquin H., Blum J.W., 2004. Glucose metabolism in lactating cows in response to isoenergetic infusions of propionic acid or duodenal glucose. J. Dairy Sci., 87, 1767-1777.

Loor J.J., Herbein J.H., 1998. Exogenous conjugated linoleic acid isomers reduce bovine milk fat concentration and yield by inhibiting de novo fatty acid synthesis. J. Nutr., 128, 2411-2419.

Loor J.J., Herbein J.H., 2003. Reduced fatty acid synthesis and desaturation due to exogenous trans $_{10}$, cis ${ }_{12}$-CLA in cows fed oleic or linoleic oil. J. Dairy Sci., 86, 1354-1369.

Loor J.J., Ueda K., Ferlay A., Chilliard Y, Doreau M., 2004. Biohydrogenation, duodenal flow, and intestinal digestibility of trans fatty acids and conjugated linoleic acids in response to dietary forage: concentrate ratio and linseed oil in dairy cows. J. Dairy Sci., 87, 2472-2485.

Loor J.J., Ferlay A., Ollier A., Doreau M. Chilliard Y., 2005. Relationship among trans and conjugated fatty acids and bovine milk fat yield due to dietary concentrate and linseed oil. J. Dairy Sci., 88, 726-740.

Mackle T.R., Kay J.K., Auldist M.J., McGibbon A.K.H., Philpott B.A., Baumgard L.H., Bauman D.E., 2003. Effects of abomasal infusion of conjugated linoleic acid on milk fat concentration and yield from pasture-fed dairy cows. J. Dairy Sci., 86, 644-652.

McClymont G.L., Vallance S., 1962. Depression of blood glycerides and milk-fat synthesis by glucose infusion. Proc. Nutr. Soc., 21, $\mathrm{X} 1$.

McCullough M.E., Sisk L.R., Smart W.W. 1969. Sodium acetate and sodium propionate as additives to aII-in-one silage rations for milk production. J. Dairy Sci., 52, 1605-1608.

Miettinen H., 1996. Effects of the ratio of ruminal propionate to butyrate on milk yield and blood metabolites in dairy cows. J. Dairy Sci., $79,851-861$.

Miller W.J., Allen N.N., 1955. The effect of sodium acetate feeding on milk and fat yield, blood sugar, and blood ketones of dairy cows. J. Dairy Sci., 38, 310-312.

Moore J.H., Christie W.W., 1981. Lipid metabolism in the mammary gland of ruminant animals. In: Lipid Metabolism in Ruminant Animals. Christie W.W. (Eds). Pergamon Press, Oxford, England, 227-245.

Offner A., Sauvant D., 2004. Prediction of in vivo starch digestion in cattle from in situ data Anim. Fd Sci. Technol., 111, 41-56.

Oldick B.S., Staples C.R., Thatcher W.W., Gyawu P., 1997. Abomasal infusion of glucose and fat-effect on digestion, production, and ovarian and uterine functions of cows. J. Dairy Sci. 80, 1315-1328.

Ørskov E.R., Grubb D.A., Kay R.N., 1977. Effect of postruminal glucose or protein supplementation on milk yield and composition in Friesian cows in early lactation and negative energy balance. Br. J. Nutr., 38, 397-405. 
Palmquist D.L., Beaulieu A.D., Barbano D.M., 1993. Feed and animal factors influencing milk fat composition. J. Dairy Sci., 76, 1753-1771.

Perfield J.W., II, Lock A.L., Pfeiffer A.M., Bauman D.E., 2004. Effects of amide-protected and lipid-encapsulated conjugated linoleic acid (CLA) supplements on milk fat synthesis. J. Dairy Sci., 87, 3010-3016.

Peterson D.G., Baumgard L.H., Bauman D.E., 2002. Short communication: milk fat response to low doses of trans10, cis $_{12}$ conjugated linoleic acid (CLA). J. Dairy Sci., 85, 1764-1766.

Peterson D.G., Matitashvili E.A., Bauman D.E., 2003. Diet-induced milk fat depression in dairy cows results in increased trans ${ }_{10}$, $\operatorname{cis}_{12}$ CLA in milk fat and coordinate suppression of mRNA bundance for mammary enzymes involved in milk fat Synthesis. J. Nutr., 133, 3098-3102.

Peyraud J.L., Widyobroto B.P., 1994. Effect of the nature and the rate of ruminal degradation of carbohydrates on site and extent of digestion in dairy cows. In: VIII Int. Symp. Ruminant Physiology. Proc. Nutr. Physiol., Willingen, Germany, 34

Pfeuffer M., Schrezenmeir J., 2006. Impact of trans fatty acids of ruminant origin compared with those from partially hydrogenated vegetable oils on CHD risk. Int. Dairy J., 16, 1383-1388.

Piperova L.S., Teter B.B., Bruckental I., Sampugna J., Mills S.E., Yurawecz M.P., Fritsche J., Ku K., Erdman R.A., 2000. Mammary lipogenic enzyme activity, trans fatty acids and conjugated linoleic acids are altered in lactating dairy cows fed a milk fat-depressing diet. J. Nutr., 130, 2568-2574.

Piperova L.S., Moallem U., Teter B.B., Sampugna J., Yurawecz M.P., Morehouse K.M., Luchini D., Erdman R.A., 2004. Changes in milk fat in response to dietary supplementation with calcium salts of trans-18:1 or conjugated linoleic fatty acids in lactating dairy cows. J. Dairy Sci., $87,3836-3844$

Reynolds C.K., Cammell S.B., Humphries D.J., Beever D.E., Sutton J.D., Newbold J.R., 2001. Effects of postrumen starch infusion on milk production and energy metabolism in dairy cows. J. Dairy Sci., 84, 2250-2259.

Rigout S., Lemosquet S., Bach A., Blum J.W., Rulquin H., 2002a. Duodenal infusion of glucose decreases milk fat production in grass silage-feed dairy cows. J. Dairy Sci., 85, 2541-2550.

Rigout S., Lemosquet S., Van Eys J.E., Blum J.W., Rulquin H., 2002b. Duodenal glucose increases glucose fluxes and lactose synthesis in grass silage-fed dairy cows. J. Dairy Sci., 85, 595-606.

Rigout S., Hurtaud C., Lemosquet S., Bach A., Rulquin H., 2003. Lactational effect of propionic acid and duodenal glucose in cows. J. Dairy Sci., $86,243-253$

Rogers G.L., Bryant A.M., McLeay L.M., 1979. Silage and dairy cow production. III. Abomasal infusions of casein, methionine, and glucose, and milk yield and composition. N. Z. J. Agric. Res., 22, 533-541.

Romo G.A., Erdman R.A., Teter B.B., Sampugnat J., Casper D.P., 2000. Milk composition and apparent digestibilities of dietary fatty acids in lactating dairy cows abomasally infused with cis or trans fatty acids. J. Dairy Sci., 83, 2609-2619.

Rook J.A., Balch C.C., 1961. The effects of intraruminal infusions of acetic, propionic and butyric acids on the yield of milk and composition of the milk of the cow. Br. J. Nutr., 15, 361-369.

Rook J.A.F., Balch C.C., Johnson V.W., 1965 Further observations on the effects of intraruminal infusions of volatile fatty acids and of lactic acid on the yield and composition of the milk of the cow. Br. J. Nutr., 19, 93-99.

Sauvant D., 1997. Conséquences digestives et zootechniques des variations de la vitesse de digestion de l'amidon chez les ruminants. INRA Prod. Anim., 10, 287-300.

Sauvant D., Perez J.M.,Tran G., 2004.Tables de composition et de valeur nutritive des matières premières destinées aux animaux d'élevage. INRA Editions, Paris, France, 301p.

Sauvant D., Schmidely P., Daudin J.J., 2005. Les méta-analyses de données expérimentales applications en nutrition animale. INRA Prod. Anim., 18, 63-73.

Sauvant D., Giger-Reverdin S., Meschy F., 2006. Le contrôle de l'acidose ruminale latente. INRA Prod. Anim., 19, 69-78.

Schmidely P., Glasser F., Doreau M., Sauvant D., 2007. Digestion of fatty acids in ruminants: a meta-analysis of flows and variation factors. 1 . Duodenal flows and intestinal absorption of total fatty acid. Animal, sous presse.

Stanley R.W., Ueyama E., 1964. Effect of feeding different roughage levels and sodium acetate in high-grain rations on milk production, milk constituents, and rumen volatile fatty acids. J. Dairy Sci., 47, 258-262

Stein D.R., Allen D.T., Perry E.B., Bruner J.C., Gates K.W., Rehberger T.G., Mertz K., Jones D., Spicer L.J., 2006. Effects of feeding propionibac- teria to dairy cows on milk yield, milk components, and reproduction. J. Dairy Sci., 89, 111125 .

Storry J.E., Rook J.A.F., 1965. The effects of diet low in hay and high in flaked maize on milkfat secretion and on the concentration of certain constituents in the blood plasma of the cow. Br. J. Nutr., 19, 101-109.

Sutton J.D., Oldham J.D., Hart I.C., 1980. Products of digestion, hormones and energy utilization in milking cows given concentrates containing varying proportions of barley or maize In: Energy Metablolism. Mount L.E. (Eds). Butterworths, London, England, 303-306.

Sutton J.D., Dhanoa M.S., Morant S.V., France J., Napper D.J., Schuller E., 2003. Rates of production of acetate, propionate, and butyrate in the rumen of lactating dairy cows given normal and low-roughage diets. J. Dairy Sci., 86, 3620-3633.

Van Soest P.J., 1963. Ruminant fat metabolism with particular reference to factors affecting low milk fat and feed efficiency. A review. J. Dairy Sci., 46, 204-216.

Van Soest P.J., Allen N.N., 1959. Studies on the relationships between rumen acids and fat metabolism of ruminants fed on restricted roughage diets. J. Dairy Sci., 42, 1977-1985.

Vanhatalo A., Varvikko T., 2003a. Effects of casein and glucose on responses of cows fed diets based on restrictively fermented grass silage. J. Dairy Sci., 86, 3260-3270.

Vanhatalo A., Varvikko T., 2003b. Effects of various glucogenic sources on production and metabolic responses of dairy cows fed grass silage-based diets. J. Dairy Sci., 86, 3249-3259.

Vik-Mo L., Emery R.S., Huber J.T., 1974. Milk protein production in cows abomasally infused with casein or glucose. J. Dairy Sci., 57 , 869-877.

Viswanadha S., Giesy J.G., Hanson T.W. McGuire M.A., 2003. Dose response of milk fat to intravenous administration of the trans $s_{10}$, cis $_{12}$ isomer of conjugated linoleic acid. J. Dairy Sci., 86, 3229-3236.

Whitelaw F.G., Milne J.S., Ørskov E.R., Smith J.S., 1986. The nitrogen and energy metabolism of lactating cows given abomasal infusions of casein. Br. J. Nutr., 55, 537-556.

Wilson G.F., Davey A.W.F., Dolby R.M., 1967. Milk composition as affected by intra-ruminal infusion of volatile fatty acids to cows on a restricted ration. N. Z. J. Agric. Res., 10, 215225.

\section{Résumé}

Les récents changements des données économiques concernant le marché et les possibilités de valorisation de la matière grasse laitière conduisent à penser qu'à l'avenir la production d'un lait un peu moins riche en matières grasses a de fortes chances d'être encouragée. Cela peut être atteint par le biais de la génétique et de la nutrition. Ce texte a pour objectif de faire l'état des connaissances sur les différents nutriments jouant sur le taux butyreux des laits et de quantifier les effets des acides acétique, butyrique et propionique, du glucose, de l'acide gras trans ${ }_{10}$ C18:1 et du trans I $_{10}$, cis $_{12}$ CLA sur le taux butyreux et le rapport taux protéique sur taux butyreux. Les travaux des cinquante dernières années sont synthétisés dans six méta-analyses des données d'essais dans lesquels les précédents nutriments ont été apportés par perfusion digestive. L'efficacité à diminuer le taux butyreux est respectivement de - 5,71, - 2,99, - 87, et - 1467 g/kg par

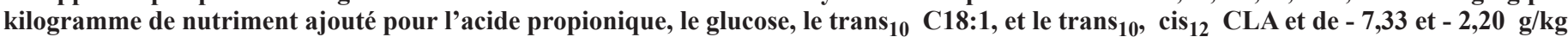
par kilogramme de nutriment apporté en moins pour les acides butyrique et acétique. Les mécanismes mis en jeux dans ces réponses sont revus. Sur la base des variations de flux de nutriments mesurées à la suite d'une augmentation de $30 \%$ de la proportion d'aliments concentrés, il ressort que les nutriments glucogéniques (acide propionique et glucose) expliqueraient $54 \%$ de la chute du taux butyreux enregistrée, les acides gras trans strans $_{10}$ C18:1 et trans tro $_{10}$, cis ${ }_{12}$ CLA) $34 \%$ et les précurseurs (acide acétique et butyrique) des acides gras synthétisés «de novo» $21 \%$. Ce travail démontre que la chute de taux butyreux observée avec des changements de régime est multifactorielle. Une approche pluri-nutriments est proposée pour remplacer l'approche mono-nutriment jusqu'ici utilisée pour essayer de prédire les changements de taux butyreux en réponse à une modification de la composition des rations. 


\begin{abstract}
Quantification of the effects of energetic nutrients on fat content of cow milk.

A decreased fat content of milk seems to be a necessity for the future at least in European countries. This can be obtained by genetic or nutritional ways. This paper tries to quantify possibilities offered by nutrition. Fat is the milk solid that can be the most easily modified in a nutritional way. Propionic acid, glucose, trans10 C18:1 and $\operatorname{trans}_{10}$, $\operatorname{cis}_{12}$ CLA are the nutrients identified to reduce milk fat content and acetic acid and butyric acid are those that increase milk fat content. Seven meta-analyses of literature data of trials giving these nutri-

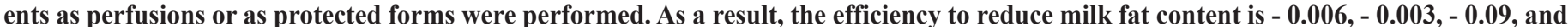
$-1.8 \mathrm{~g} / \mathrm{kg}$ per gram of added nutrient for propionic, glucose, $\operatorname{trans}_{10} \mathrm{C18}: 1$, and trans ${ }_{10}, \mathrm{cis}_{12}$ CLA and - 0.007, - 0.002 g/kg per gram of subtracted nutrient for butyric and acetic acids respectively. The mechanisms involved in these responses are reviewed. In the decrease of milk fat content induced by a $30 \%$ increase of concentrate, glucogenic precursors (propionic acid and glucose) explain $54 \%$ of the drop of milk fat content, trans $s_{10}$ containing fatty acids (trans $s_{10}$ C18:1 and $\operatorname{trans}_{10}$, cis 12 CLA) explain $34 \%$, and precursors of de novo fatty acid synthesis (acetic, and butyric acids) explain $21 \%$. In conclusion, a decrease of milk fat content with some diets is multi-factorial, and a pluri-nutrient approach is proposed in replacement of the usual mono-nutrient approach in order to understand the variations of milk fat content.
\end{abstract}

RULQUIN H., HURTAUD C., LEMOSQUET S., PEYRAUD J.-L., 2007. Effet des nutriments énergétiques sur la production et la teneur en matière grasse du lait de vache. INRA Prod. Anim., 20, 163-176. 